OPEN ACCESS

Edited by:

Elio Acquas,

University of Cagliari, Italy

Reviewed by:

Yedy Israel,

University of Chile, Chile

Enrico Sanna,

University of Cagliari, Italy

${ }^{*}$ Correspondence:

Juan Carlos Molina

juancmolina2003@hotmail.com.ar;

jmolina@immf.uncor.edu

Specialty section:

This article was submitted to Learning and Memory, a section of the journal Frontiers in Behavioral Neuroscience

Received: 28 November 2019 Accepted: 17 February 2020

Published: 10 March 2020

Citation:

Miranda-Morales RS, D'Aloisio G, Anunziata F, Abate $P$ and Molina JC (2020) Fetal Alcohol Programming of

Subsequent Alcohol Affinity: A Review Based on Preclinical, Clinical and Epidemiological Studies.

Front. Behav. Neurosci. 14:33. doi: 10.3389/fnbeh.2020.00033

\section{Fetal Alcohol Programming of Subsequent Alcohol Affinity: A Review Based on Preclinical, Clinical and Epidemiological Studies}

\author{
Roberto Sebastián Miranda-Morales ${ }^{1,2}$, Genesis D'Aloisio ${ }^{1}$, Florencia Anunziata ${ }^{1}$, \\ Paula Abate ${ }^{3}$ and Juan Carlos Molina ${ }^{1,2 *}$ \\ ${ }^{1} /$ nstituto de Investigación Médica Mercedes y Martín Ferreyra, INIMEC-CONICET- Universidad Nacional de Córdoba,

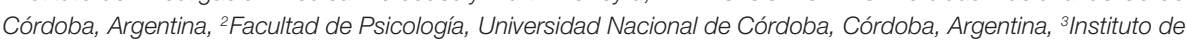 \\ Investigaciones Psicológicas, Facultad de Psicología, Universidad Nacional de Córdoba, Córdoba, Argentina
}

The anatomo-physiological disruptions inherent to different categories of the Fetal Alcohol Spectrum Disorder do not encompass all the negative consequences derived from intrauterine ethanol $(\mathrm{EtOH})$ exposure. Preclinical, clinical and epidemiological studies show that prenatal $\mathrm{EtOH}$ exposure also results in early programming of alcohol affinity. This affinity has been addressed through the examination of how EtOH prenatally exposed organisms recognize and prefer the drug's chemosensory cues and their predisposition to exhibit heightened voluntary $\mathrm{EtOH}$ intake during infancy and adolescence. In altricial species these processes are determined by the interaction of at least three factors during stages equivalent to the 2 nd and 3rd human gestational trimester: (i) fetal processing of the drug's olfactory and gustatory attributes present in the prenatal milieu; (ii) EtOH's recruitment of central reinforcing effects that also imply progressive sensitization to the drug's motivational properties; and (iii) an associative learning process involving the prior two factors. This Pavlovian learning phenomenon is dependent upon the recruitment of the opioid system and studies also indicate a significant role of EtOH's principal metabolite (acetaldehyde, ACD) which is rapidly generated in the brain via the catalase system. The central and rapid accumulation of this metabolite represents a major factor involved in the process of fetal alcohol programming. According to recent investigations, it appears that ACD exerts early positive reinforcing consequences and antianxiety effects (negative reinforcement). Finally, this review also acknowledges human clinical and epidemiological studies indicating that moderate and binge-like drinking episodes during gestation result in neonatal recognition of EtOH's chemosensory properties coupled with a preference towards these cues. As a whole, the studies under discussion emphasize the notion that even subteratogenic $\mathrm{EtOH}$ exposure during fetal life seizes early functional sensory and learning capabilities that pathologically shape subsequent physiological and behavioral reactivity towards the drug.

Keywords: fetal alcohol programming, odor and taste, reinforcement, anxiety, associative learning, acetaldehyde, opioid system 


\section{INTRODUCTION}

Two drug-related phenomena act as the foundation for the present review: (i) among other drugs of abuse, ethanol (EtOH) recruits non-associative and associative learning capabilities of the organism; and (ii) age of onset of EtOH-related experiences represents a critical factor determining later use and abuse of this psychotropic agent. Both issues are intrinsically related to the concept of early-life adaptations to environmental disturbances that increase susceptibility to diseases in later life (Barker et al., 2009; Hay, 2009; Calkins and Devaskar, 2011). Under the framework of this vision, we will primarily examine fetal alcohol programming processes, which according to preclinical, clinical and epidemiological studies, represent a critical factor in the structure of subsequent affinity for the drug and the future well-being of the organism. To accrue this goal the present review requires the analyses of the recruitment of early sensory capabilities when the drug invades the prenatal milieu, early EtOH's motivational properties and the likelihood of learning processes combining both factors. Other critical elements that are needed to understand short- and long-lasting consequences of fetal alcohol programming are related with the critical participation of EtOH's principal metabolite (acetaldehyde, ACD), how the endogenous system modulates the reinforcing effects of the drug and the effects of the interaction between prenatal and postnatal experiences that shape alcohol recognition, discrimination and preference patterns.

From a general perspective, there is no doubt that EtOH's teratogenic potential represents the main issue linking embryonic and fetal life with maternal consumption of the drug. The identification of a syndrome (Fetal Alcohol Syndrome, FAS) representing one of the major congenital causes of mental disabilities (Lemoine et al., 1968; Jones et al., 1973) as well as the subsequent recognition and definition of Fetal Alcohol Spectrum Disorders (Riley and McGee, 2005; Riley et al., 2011; Mattson et al., 2019) have guided most of the literature concerning early development and EtOH intoxication. According to the US National Institutes of Health (ncbi.nlm.nih.gov; October 2019), approximately 17,000 articles arise when linking the terms "fetal" and "alcohol." Within this considerable number of peer-reviewed studies, it is possible to detect an early publication that explicitly examined the consequences of fetal chronic exposure to EtOH upon subsequent intake patterns of the drug (Bond and Di Giusto, 1976). According to these authors, and based on an animal model frequently employed to assess EtOH's teratogenic properties, voluntary intake of the drug in an altricial species such as the rat, increases as a function of prenatal exposure to this psychotropic agent. There were methodological problems in this study since experimental pregnant rats consumed a liquid diet containing Sustagen (a milk-based supplement) and ethanol while control mothers were fed on lab chow. This obviously implies possible differential nutritional effects that can also lead to ethanol intake changes in the progeny limiting the conclusions of this study. In addition, given the lack of prior information concerning this phenomenon, it was certainly difficult to determine is such an effect was modulated by factors such as alterations in neurotransmitter systems that sensitize the organism to EtOH's motivational properties (e.g., positive reinforcing effects and/or negative reinforcing effects primarily related with the drug's antianxiety consequences), comorbidity of neurobehavioral disorders (hyperactivity, attentional deficits, depression, impulsivity), disruptions in basic sensory capabilities that impede or alter olfactory and gustatory discrimination processes, etc. Probably none of these modulators can now be dismissed. It is our expectation that the present review will provide at least partially, notions related with the fact that early experiences with the drug recruit functional capabilities of the organism that result in subsequent alcohol affinity. As will be analyzed this recruitment can be established when employing even subteratogenic levels of EtOH exposure. Through the examination of this phenomenon we hope to provide an expansion of the pre-existing vision of neurobehavioral disorders that need to be prevented, diagnosed or treated in children and adolescents with an early positive EtOH history.

The present review will be organized as follows: (i) a first section, primarily centered on preclinical studies, analyses different experimental strategies alluding to fetal capabilities of altricial mammals related to the detection and discrimination of EtOH's sensory attributes; (ii) a second item, also based in animal studies, incorporates the notion of EtOH's reinforcing effects that promote associative learning memories leading to heightened EtOH affinity; (iii) the third section emphasizes the need to consider the drug's principal metabolite (ACD) as a critical factor modulating EtOH's reinforcing effects; (iv) the role of the endogenous opiate system modulating prenatal EtOH reinforcement is additionally considered via animal behavioral and psychopharmacological studies; and (v) Finally, the last section of the review is devoted to highlighting human clinical and epidemiological studies endorsing the notion that prenatal $\mathrm{EtOH}$ experiences have a major impact on the development of subsequent EtOH affinity. As will be observed, this human section has been organized to depict the analogies and homologies existing between animal and human findings.

\section{DO FETUSES PERCEIVE EtOH'S CHEMOSENSORY PROPERTIES?}

Fetal and neonatal sensory discrimination capabilities have been described in different altricial species (rabbits, sheep, rats) including humans (Lecanuet et al., 1995; Schaal et al., 2002, 2004; Clark-Gambelunghe and Clark, 2015; Fulgione et al., 2017). Neuroethological studies indicate that chemosensory systems rapidly become functional in the uterus (Molina et al., 1999, 2007a; Schaal et al., 2004; Bloomfield et al., 2017). This development is required for essential survival purposes related to subsequent maternal attachment processes including the discrimination and recognition of the main nutrients (colostrum and milk) that will be provided both peri- and neonatally (Cernoch and Porter, 1985; Makin and Porter, 1989; Marlier et al., 1998; Miller and Spear, 2009; Díaz-Marte et al., 2010; Corona and Lévy, 2015). In accordance with Nicolaidis (Nicolaïdis, 2008) intrauterine experience with flavors derived 
from the mother's diet is swallowed by the fetus generating the activity of a functional olfactogustatory system. First experiences with flavors occur prenatally via the accumulation of sensory cues in the amniotic fluid yielding olfactory, gustatory and trigeminal stimulation that is also observed when these cues are present in breastmilk (Mennella and Beauchamp, 1991; Beauchamp and Mennella, 2011; Forestell and Mennella, 2017); phenomena that serve to establish orosensory learning processes that reunite the basic characteristics of a prenatal and/or perinatal imprinting process.

Maternal EtOH consumption also results in the accumulation of the drug in the amniotic fluid as well as in breastmilk (Bachmanov et al., 2003; Molina et al., 2007b). The low molecular weight of this psychotropic agent permits its passage through the placenta and the levels attained in the amniotic fluid and fetal blood are comparable to those existing in maternal plasma (Szeto, 1989; Hayashi et al., 1991; Domínguez et al., 1998). As indicated by Glendinning et al. (2017), fetal perception of the drug's chemosensory properties in the rat can be established through two non-mutually exclusive pharmacokinetic mechanisms; humoral and intraoral. The presence of the drug in the bloodstream of the immature organism is capable of generating hematogenic stimulation of chemosensory receptors (Molina and Chotro, 1989a,b; Molina et al., 1989) while the presence of $\mathrm{EtOH}$ in the amniotic fluid directly stimulates olfactory, gustatory and trigeminal receptors (Glendinning et al., 2017).

At least four reviews have acknowledged the consequences of fetal exposure to the drug's chemosensory attributes upon later recognition and preference to these cues (Bachmanov et al., 2003; Spear and Molina, 2005; Molina et al., 2007b; Abate et al., 2008). Hence, the present section will only be devoted to summarizing the main findings discussed in such reviews which reinforce the notion that fetal alcohol perception critically intervenes in how the organism later relates to the drug. The following issues will be presented as a function of different experimental strategies analyzing this specific phenomenon.

A first preclinical approach emerges from studies performed in near term rat fetuses (21 gestational days) via direct administration of minimal amounts of $\mathrm{EtOH}$ in the amniotic fluid (40 $\mu \mathrm{l}$ of a $6 \% \mathrm{v} / \mathrm{v} \mathrm{EtOH}$ solution) or a novel scent (lemon). Ten minutes later pups were delivered via cesarean surgical procedures (Chotro and Molina, 1990). During the 2nd week of postnatal life, pups were tested in an olfactory preference test as well as in terms of $\mathrm{EtOH}$ intake patterns. The sensory cue presented in the amniotic sac was the one preferred in the olfactory evaluation. In addition, pups with a short antenatal EtOH experience were the ones exhibiting heightened levels of EtOH ingestion (Dominguez et al., 1993). Utilizing a similar experimental approach, it was also observed, almost immediately after birth, that pups exposed prenatally to EtOH exhibited clear behavioral and physiological (bradycardia) responses indicative of an orienting response to the smell of the drug (Chotro and Molina, 1992). This antenatal experience, that was not sufficient to generate pharmacologically relevant EtOH levels in the fetus, was also observed to potentiate infantile alcohol-odor conditioned preferences when the odor of the drug was paired with a sweet positive reinforcer (Chotro et al., 1991).

A second experimental approach validating the importance of prenatal exposure to EtOH's sensory properties has been employed during a fetal stage of brain development in the rat analogous to the 2nd human trimester (Dobbing and Sands, 1979; Tran et al., 2000). During this stage rats and humans exhibit a functional olfactogustatory system (Molina et al., 1999; Bloomfield et al., 2017) as well as significant innervations of target fields of the oral trigeminal system (Mbiene and Mistretta, 1997). The procedure normally involves maternal EtOH intoxication utilizing subteratogenic doses $(0.5-2.0 \mathrm{~g} / \mathrm{kg})$ that are intragastrically administered during the last 4 days of gestation (gestational days 17-20). This protocol yields comparable EtOH levels in the amniotic fluid, fetal and maternal blood (range according to the doses previously mentioned: 50-160 mg/dl; (Domínguez et al., 1996). The first study utilizing this approach indicated that $\mathrm{EtOH}$ was not sufficient to cause teratogenic disruptions related to placenta weights, umbilical cord lengths, offspring's body weights, weights and/or size of the olfactory bulbs, cerebral hemispheres, and cerebellum. Furthermore, subsequent research indicates that this EtOH exposure procedure does not affect neural migration processes which allow the appropriate synaptic organization of the glomeruli of the principal olfactory bulbs (Pueta et al., 2011). Yet, fetal early experience with EtOH had a dramatic effect upon perinatal responsiveness to the smell of the drug. Pups pretreated with 1.0 or $2.0 \mathrm{~g} / \mathrm{kg} \mathrm{EtOH}$ consistently showed a marked decrement in their motor activity when stimulated with the scent of the drug. This reaction was markedly different from the one caused by a novel citric scent (Domínguez et al., 1996). We later observed that perinatal infusion of EtOH concentrations similar to those encountered in the amniotic fluid also exerted a sedative effect upon a motor activity (Domínguez et al., 1998). This effect was very similar to the one generated by the amniotic fluid in rat pups with no prior history with the drug. The biological fluid had no sedative effects in pups pretreated with EtOH. In other words, fetal alcohol experience determined a similar profile of perinatal responsiveness to EtOH's sensory cues as the one encountered when control perinates were confronted with a relevant biological sensory cue. Experience with the sensory cues of the amniotic fluid is known to intervene in the acceptance of colostrum and milk (Marlier et al., 1998; Al Aïn et al., 2013; Schaal et al., 2013) or even to act as an appetitive conditioned stimulus (CS; Chotro et al., 2007). These results seem to strengthen the hypothesis of a sensoryimprinting phenomenon generated via prenatal $\mathrm{EtOH}$ exposure (Nicolaïdis, 2008).

Is this particular prenatal experience sufficient to modify EtOH affinity later in life? The answer is affirmative and once again implies fetal memories relative to EtOH's chemosensory attributes. During infancy, near term rat fetuses exposed to maternal EtOH intoxication not only ingest higher amounts of $\mathrm{EtOH}$ but also show drinking preferences when confronted with the configuration of a sucrose-quinine solution (Domínguez et al., 1998). In genetically heterogeneous rats, this gustatory combination has been demonstrated to act as a psychophysical 
equivalent relative to the EtOH's taste (Di Lorenzo et al., 1986; Kiefer, 1995; Bachmanov et al., 2003). It has also been demonstrated that heightened $\mathrm{EtOH}$ intake patterns are mainly generated when fetal experience occurs during the last two gestational days (19 and 20). This brief temporal exposure is also capable of increasing $\mathrm{EtOH}$ palatability (Díaz-Cenzano and Chotro, 2010).

Rat and human neonates detect even minimal amounts of EtOH in maternal milk [rats: $175 \mathrm{mg} / \mathrm{dl}$ following maternal intoxication with $2.5 \mathrm{~g} / \mathrm{kg}$ EtOH (Pepino et al., 1999); humans: $50 \mathrm{mg} / \mathrm{dl}$ following the intake of a single beer (Mennella and Beauchamp, 1991, 1993; Mennella, 1997)]. It has also been demonstrated that in rats, EtOH maternal intoxication ( 1.0 or $2.0 \mathrm{~g} / \mathrm{kg}$ ) during late pregnancy exacerbates offspring's consumption of milk contaminated with the above mentioned minimal amounts of the drug without affecting the consumption of the uncontaminated nutrient (Pueta et al., 2008).

The early recognition of EtOH's sensory attributes as a function of maternal EtOH intoxication during late pregnancy has also been investigated relative to the effects of the drug upon breathing plasticity. Cullere et al. (2015) have observed that brief fetal EtOH experiences in rodents disrupt neonatal breathing patterns when the organism is re-exposed to the toxic effects of the drug. Most importantly, this detrimental effect is exacerbated under the presence of EtOH odor. Similar results have been reported in rats during postnatal days 3-9; a developmental stage that partially overlaps with the 3rd human gestational trimester characterized by a brain growth spurt (Macchione et al., 2016). In subsequent items of this review, these issues will be re-examined as a function of associative learning processes based on EtOH's sensory cues and the drug's motivational effects.

The analysis of sensory-related memories emerging from prenatal EtOH experiences has also been addressed through animal models based on the use of moderate to high levels of EtOH throughout most of the gestational period. The most frequent model that has been utilized is known to exert teratogenic effects and implies a progressive increase in the amount of $\mathrm{EtOH}$ provided to the mother via a liquid diet (Miller, 1992). Based on this animal model, neurophysiological responsiveness to different odorants including EtOH was mapped across the olfactory epithelium. The main findings observed in infants prenatally exposed to the drug indicate a tuned neurophysiological response to $\mathrm{EtOH}$ odor despite an altered general response to alternative odorants. This result was also supported by a specific odorant-induced reflexive sniffing response to $\mathrm{EtOH}$ odor emerging from a positive prenatal history with the drug (Youngentob et al., 2007; Eade et al., 2010). Chronic prenatal EtOH exposure also resulted in heightened voluntary EtOH intake during early postnatal life and adulthood (Youngentob et al., 2007). When focusing on the gustatory system, fetal EtOH exposure resulted in the taste-mediated acceptability of EtOH and a diminished aversion to the drug's quinine-like taste component (Youngentob and Glendinning, 2009). In a recent study, the research group of Glendinning et al. (2017) has provided new evidence concerning fetal alcohol exposure reprogramming of the peripheral taste and trigeminal systems. The main findings indicate that prenatal $\mathrm{EtOH}$ diminishes aversive flavor attributes of the drug such as its bitter taste and the burning sensation mediated by the trigeminal system.

Sensory persistence of fetal-alcohol related chronic exposure was also assessed during adolescence utilizing an animal social transmission paradigm involving the perception of EtOH odor. The paradigm is based on the interactions between a sober organism (observer) and an intoxicated counterpart (demonstrator) which provides sensory information of the drug via direct elimination processes (e.g., alveolar excretion, urination, salivation, et cetera (Fernández-Vidal and Molina, 2004; March et al., 2013d). A positive prenatal alcohol history promoted social interactions with an intoxicated peer and the juvenile re-exposure experience subsequently enhanced EtOH odor response as assessed in a whole-body plethysmograph (Eade and Youngentob, 2009). When configuring the neurophysiological and behavioral studies conducted by Youngentob and Glendinning (2009) the title of one of their articles clearly summarizes the impact of chronic fetal alcohol exposure upon EtOH affinity: "Fetal EtOH exposure increases EtOH intake by making it smell and taste better."

\section{A HOLISTIC VIEW OF FETAL ALCOHOL PROGRAMMING PROCESSES: IS SENSORY FAMILIARIZATION SOLELY RESPONSIBLE FOR SUBSEQUENT ETOH AFFINITY? THE NEED TO CONSIDER EARLY EtOH'S MOTIVATIONAL EFFECTS}

According to the information presented in the preceding item, fetuses detect EtOH's sensory attributes and memories arising from these early experiences allow latter discrimination of these cues and preference to such stimuli. Is sensory familiarization solely responsible for subsequent EtOH affinity? From a pharmacokinetic perspective, the studies previously reported based on maternal EtOH intoxication imply the juxtaposition of the drug in the amniotic fluid and its presence in fetal blood and brain. Hence, in terms of potential associative learning processes (e.g., pavlovian or classical conditioning), the requirement of temporal contiguity between specific sensory cues and physiological effects of the drug is met.

It can be argued that when animal studies were conducted via direct $\mathrm{EtOH}$ contamination of the amniotic fluid while avoiding fetal intoxication (Chotro and Molina, 1990, 1992; Chotro et al., 1991) the main phenomenon determining subsequent $\mathrm{EtOH}$ recognition and preference obeyed to familiarization with EtOH's sensory cues. Even under these circumstances, biologically relevant stimuli were found to modulate the memories arising from such experiences. The administration of the drug into the amniotic sac took place only $10 \mathrm{~min}$ prior to cesarean delivery. Immediately after delivery, neonatal bodily stimulation was provided to ensure optimal survival rates. This tactile manipulation mimics maternal stimulating effects which, modulated through the endogenous opiate system, acts as an appetitive unconditioned stimulus (US) that is rapidly associated 
with pre-existing or simultaneously presented olfactory cues (Leon, 1987; Ronca and Alberts, 1994; Roth and Sullivan, 2006; Raineki et al., 2010). Indeed, when considering EtOH administration into the amniotic fluid and its contingency with activating tactile stimulation, it was observed that sensory preferences were highly dependent upon optimal temporal contiguity between these factors (Molina et al., 1999). In other words, the phenomenon under consideration complied with the notion of the acquisition and retention of a conditioned response.

There are numerous examples that endorse the capability of the fetus to learn conditioned responses when pairing a relatively neutral stimulus (e.g., an odorant) with different biologically relevant events. Conditioned taste aversions have been reported in near term rat fetuses when pairing a tastant (apple juice) with the emetic effects of lithium chloride. These aversions are manifested in multiple ways: avoidance of maternal nipples scented with such tastant or spending less time over shavings that contain this gustatory cue (Stickrod et al., 1982) as well as a noticeable delay to traverse a runaway scented with apple to gain access to the mother (Smotherman, 1982). Acute hypoxia induced by clamping the umbilical cord can also lead to odor conditioned aversions (Hepper, 1991) while on the contrary, cessation of hypoxia leads to odor conditioned preferences (Hepper, 1993).

EtOH can be considered as a drug that depending on factors such as dose, age, genetic predisposition, comorbidity with other neurobehavioral disorders, etc. can exert differential triphasic motivational effects. EtOH intoxication promotes positive and antianxiety effects as well as aversive consequences (Pautassi et al., 2009). Positive reinforcing effects play a significant role in the initiation, maintenance of alcohol intake, seeking behavior of the drug as well as in patterns of abuse of this psychotropic agent. These processes can also be modulated by that the drug's amelioration of aversive states such as anxiety and dysphoria. The progressive maturation of the hepatic system allows the accumulation of peripheral ACD which exerts both gastrointestinal distress and sedative effects known to act as aversive stimuli (Cunningham et al., 2000). Each of these motivational effects can support associative learning given its temporal association with interoceptive or environmental CSs.

When the pregnant female is intoxicated, it is difficult to discern whether fetuses only learn about the sensory components of the drug, its unconditioned effects or the association between these factors. The first animal study that was meant to address these possibilities was originally based on a pharmacokinetic approach involving the distribution of a non-EtOH olfactory cue (cineol, the main component of eucalyptus oil) that easily crosses the placenta and exerts no physiological consequences on the fetus. Cineol can be easily traced in terms of concentration and temporal duration in the amniotic fluid. The strategy was to explicitly associate or not the presence of this CS with the state of fetal $\mathrm{EtOH}$ intoxication. These experiences took place during gestational days of 17-20. Three weeks later pups originally exposed to the explicit association between cineol and $\mathrm{EtOH}$ intoxication exhibited conditioned orofacial responses when re-exposed to the odorant (Abate et al., 2000). Utilizing a similar strategy, a test was conducted based on the newborn's first suckling response. The test consisted in the evaluation of neonatal attachment to a surrogate nipple that delivers milk. In pups prenatally exposed to an optimal contingency involving cineol and $\mathrm{EtOH}$ intoxication, the presence of the odorant promoted heightened suckling behavior of the surrogate nipple. In addition, this effect was potentiated if neonates were re-exposed to a similar state of intoxication as the one experienced in utero; a phenomenon that appears to indicate reactivation of the original associative memory (Abate et al., 2002).

The hypothesis of associative learning mechanisms received additional support through a series of preclinical studies where cesarean delivered pups were tested utilizing two alternative conditioning procedures. The first one utilized the surrogate nipple as a CS paired with an intraoral infusion of EtOH while the second one employed an olfactory CS associated with a similar infusion. Pups exhibited pharmacologically relevant levels of $\mathrm{EtOH}$ in blood and in both cases, the presence of the odorant elicited heightened responsiveness to the surrogate nipple (Cheslock et al., 2001). The efficacy of $\mathrm{EtOH}$ as a positive reinforcer was also detected when utilizing either intraperitoneal or intracisternal (directly into the cisterna magna) administrations of the drug (Petrov et al., 2003; Nizhnikov et al., 2007).

Taking into account the preceding studies, new experimental approaches were focused on the interaction between prenatal experience with the drug and its subsequent reinforcing effects. Near term rat fetuses were exposed to a moderate EtOH dose and following cesarean delivery they were subjected to paired or unpaired experiences comprising a surrogate nipple and different EtOH doses $(0.00,0.25,0.50$ or $0.75 \mathrm{~g} / \mathrm{kg}$ ) which were intraperitoneally injected. A positive antenatal history with the drug increased the magnitude of appetitive conditioned responses to the nipple mediated by $\mathrm{EtOH}$ intoxication and also increased the range of doses yielding a reinforcing effect (Nizhnikov et al., 2006). This phenomenon alludes to a sensitization effect relative to the drug's motivational properties.

Further evidence indicative of prenatal EtOH sensitization was detected in infants subjected to an operant conditioning procedure where a sweet tastant (sucrose) served as a reinforcer. After operant training, a moderate EtOH dose $(0.5 \mathrm{~g} / \mathrm{kg})$ was paired with the sweet taste. In pups prenatally exposed to $\mathrm{EtOH}$, this association enhanced sucrose reinforcement and also increased resistance to extinction of the operant response (Culleré et al., 2014). Progressive sensitization to the US facilitates associative learning processes probably by impeding habituation to conditioned signals and strengthening the contingency between these signals and the US (Çevik, 2014). In the case of early EtOH exposure, this entanglement of non-associative and associative learning effects may help to explain the persistence of memories leading to $\mathrm{EtOH}$ affinity. Heightened voluntary adolescent EtOH consumption has been detected following brief experiences with the drug during late gestation (Fabio et al., 2015) as well as when drug exposure occurred during most of the gestational period (Eade et al., 2016). In the first case, it was also observed that prenatal EtOH exposure also mitigated the aversive effects of relatively high 
doses of the drug that are sufficient to generate conditioned taste aversions. Furthermore, late prenatal EtOH exposure has been observed to decrease neural activity within the infralimbic cortex, an area implicated in the extinction of drug-mediated associative memories (Fabio et al., 2013).

Heightened early sensitivity to EtOH's reinforcing effects has also received support from operant conditioning procedures adapted to the sensory and motor capabilities of the perinate. It was originally demonstrated that perinatal behaviors (nosepoking and front limb movements) deployed to stimulate the mammary gland and to facilitate nipple attachment increase as a function of intraoral delivery of maternal milk (Arias et al., 2007). This technique was adapted to assess the reinforcing value of different EtOH solutions. Operant conditioning mediated by the drug rapidly occurred and perinates exhibited dose-dependent blood $\mathrm{EtOH}$ concentrations. At the beginning of an extinction process, pups reinforced with EtOH were also found to exhibit exacerbated seeking behaviors of the drug (Bordner et al., 2008). As assessed through this operant paradigm, late prenatal exposure to EtOH enhances the reinforcing effects of the drug as well as of a taste-related psychophysical equivalent such as the configuration between sucrose and quinine (March et al., 2009). This taste configuration has no reinforcing effects in pups without prior prenatal EtOH exposure. Apparently, the association between EtOH's sensory attributes and the reinforcing effects of the drug allows the relatively neutral gustatory components later act as second-order reinforcers (Molina et al., 2007a).

Notice that the above-summarized studies seem to indicate that EtOH primarily acts as the appetitive US when employing classical conditioning paradigms or as a positive reinforcer when examining animal operant learning. In some of these studies, EtOH doses yielding relatively high blood and brain levels of the drug were employed. In no case, conditioned taste or odor aversions were detected. These aversions have been observed during infancy, adolescence and adulthood. More specifically, EtOH-mediated conditioned aversions are rapidly established in 10-day-old or older rats (for a detailed ontogenetic revision on this matter see Pautassi et al., 2009). Some studies have utilized high $\mathrm{EtOH}$ doses (e.g., $3.0 \mathrm{~g} / \mathrm{kg}$ ) during stages equivalent to the 2 nd or 3 rd human gestational trimester. In older animals, these doses exert highly aversive effects that seem to provoke emetic-like effects as the ones induced by lithium chloride (Arias et al., 2007; Pautassi et al., 2008). One of these studies was conducted during late prenatal life where pregnant females received binge-like exposures to the drug operationalized through intragastric administration of a $3.0 \mathrm{~g} / \mathrm{kg}$ dose (peak blood and amniotic fluid levels were approximately equivalent to $200 \mathrm{mg} / \mathrm{dl}$; Chotro et al., 2009). Direct elimination of the drug (e.g., alveolar excretion and salivation) or hematogenic stimulation of sensory receptors promotes associative learning comprising EtOH's chemosensory cues and the drug's interoceptive effects (Molina et al., 1989). As described, fetuses exhibit associative learning given the contingency between sensory and toxic effects of EtOH. Dams treated with the above-mentioned dose later exhibited an initial rejection of an EtOH solution in a voluntary intake test suggestive of a conditioned orosensory aversion. On the contrary, their offspring showed alcohol affinity during infancy.

As can be observed, noticeable ontogenetic differences emerge when considering the motivational properties of the drug. Fetuses as well as neonates (7-8 day old rats) treated with a high EtOH dose $(3.0 \mathrm{~g} / \mathrm{kg})$ later exhibit enhanced drug palatability and heightened predisposition to consume this psychotropic agent. At 10 days of age opposite outcomes (disgust reactions and intake decrements) are detected following toxic experiences generated by a similar dose (Arias and Chotro, 2006). As indicated by the authors of this last study, there exists an ontogenetic change in the perception of EtOH's reinforcing properties that coincides with the end of a sensitive period for learning preferences in pups younger than 9 days of age (Sullivan et al., 2000; Roth and Sullivan, 2003). During this sensitive period, certain neurobiological factors (immaturity of the amygdala, low brain corticosterone levels) weaken the capability of the organism to learn certain aversions (Debiec and Sullivan, 2017). Nevertheless, when considering EtOH intoxication there are other important metabolic factors that should be considered when examining the early predisposition to learn conditioned preferences and to exhibit resistance to the drug's aversive effects. This topic focuses on the motivational role of EtOH's first metabolite (ACD) during early ontogeny.

\section{ACETALDEHYDE METABOLISM DURING EARLY ONTOGENY: EARLY MOTIVATIONAL EFFECTS OF EtOH'S PRINCIPAL METABOLITE}

Peripheral and central production of ACD critically modulates sensitivity to EtOH's motivational properties. In genetically selected animals in terms of alcohol affinity as well as in genetically heterogenous rats and mice, the central production of ACD via the catalase system represents a critical factor modulating EtOH's positive reinforcing effects (Quertemont, 2004; Israel et al., 2015; Peana et al., 2015). The induction of the activity of this enzymatic system potentiates EtOH's motor stimulating effects (Correa et al., 2001). This stimulatory effect has been considered as an index of positive rewarding central effects of different drugs of abuse (Wise and Bozarth, 1987; Orsini et al., 2004). Correa et al. (2001) showed that in adult rodents pre-treatment with 3 -amino-1H,2,4-triazole, a well-known catalase inhibitor, before EtOH administration, significantly reduces EtOH-induced motor stimulation as well as brain catalase activity. In the periphery, $\mathrm{EtOH}$ is mainly metabolized into ACD via hepatic alcohol dehydrogenase enzymes and the accumulation of the metabolite has been primarily associated with aversive motivational effects (Escarabajal et al., 2003; Sanchis-Segura et al., 2005). Given the hepatic immaturity of fetuses and neonates, the capability to metabolize $\mathrm{EtOH}$ into ACD is markedly lower than the one observed during infancy, adolescence and adulthood (Kelly et al., 1987). On the contrary, the activity of the central catalase system negatively correlates with age. The peak activity 
level of this brain enzymatic system is observed during late gestation and in neonates (Del Maestro and McDonald, 1987). Given this pharmacokinetic profile during early ontogeny, EtOH intoxication implies: (i) a significant accumulation of ACD in the brain; a factor positively correlated with EtOH's reinforcing effects; and (ii) hepatic immaturity delaying peripheral accumulation of the metabolite which potentially reduces the aversive effects of the drug upon the gastrointestinal system (March et al., 2013b). Considering both processes it appears that, from a metabolic perspective, the balance between central and peripheral ACD production and accumulation during early ontogeny favors positive motivational effects of EtOH.

Different studies based on early EtOH or ACD central administration validate the notion that the metabolite is critical in terms of determining or modulating positive reinforcement. In cesarean delivered rat neonates, only one conditioning trial where an odor was associated with central $\mathrm{EtOH}$ administration, was sufficient to generate an olfactory conditioned preference. This effect was completely absent when the catalase system was inhibited with sodium azide (Nizhnikov et al., 2007). Sodiumazide treatment did not affect motor activity when pups were stimulated with the olfactory CS during conditioning or when evaluating nipple attachment at the test; results indicating that neither perception of the CS or the pup's motor capabilities changed as a function of this drug treatment. Despite these null effects, a follow-up experiment was conducted to test whether the inhibitory effects of sodium azide upon EtOH reinforcement were specific relative to catalase inhibition or if they were merely related to negative consequences upon sensory or learning capabilities of the organism. Rather than employing $\mathrm{EtOH}$ as a reinforcer, the study was conducted with the central administration of an endogenous kappa opioid receptor agonist (dynorphin A-13) also known to exert positive reinforcement early in life. The effects of this agonist are independent of metabolic processes corresponding to the catalase system. The study clearly indicated the reinforcing effects of dynorphin that were not affected by inhibition of the catalase system.

Based on these results, studies were performed in cesarean delivered pups intracisternally administered with an EtOH dose (100 $\mathrm{mg} \%$ ) that exerts positive reinforcing effects or an ACD dose $(0.35 \mu \mathrm{mol})$ also known to exert psychomotor stimulating effects in adults. Both EtOH and ACD activate the mesolimbic dopamine system which is critical in mediating reinforcing effects of different drugs of abuse (Melis et al., 2007; Diana et al., 2008). Brain administration of the drug or its first metabolite was sufficient to promote the rapid acquisition of conditioned olfactory preferences which was markedly inhibited when sequestering central ACD through the use of d-penicillamine (March et al., 2013a,c). A recent study also showed that maternal administration of d-penicillamine significantly decreases the prenatal reinforcing effects of EtOH when considering different levels of expression of alcohol affinity: (i) attractiveness to EtOH odor as assessed through an odor crawling locomotion neonatal test; (ii) operant responding supported by EtOH reinforcement at postnatal day 5; and (iii) EtOH intake during the second postnatal week (Gaztañaga et al., 2017).
Further support relative to the importance of ACD in the regulation of EtOH's reinforcing effects was provided by a meta-analytical perspective. The question that guided this approach was the examination of a possible correlation existing between levels of catalase activity and $\mathrm{EtOH}$ affinity across ontogeny. As a first step, developmental changes in catalase activity based on average scores (U/mg protein) observed in cerebral hemispheres, striatum, cerebellum and brain stem were taken into account (Del Maestro and McDonald, 1987). As previously mentioned, there is a gradual decrease in the levels of catalase activity as a function of increasing age. Values corresponding to different age groups were linearly correlated with blood EtOH levels derived from alcohol consumption tests performed at similar ages (Truxell and Spear, 2004; Truxell et al., 2007). Spontaneous EtOH intake also decreases gradually across development. This inferential strategy indicated highly significant positive correlations when considering voluntary consumption of $15 \% \mathrm{v} / \mathrm{v}$ (Pearson's correlation coefficient, $r=0.82$ ) or $30 \% \mathrm{v} / \mathrm{v} \mathrm{EtOH}$ solutions ( $r=0.93$; March et al., 2013b).

Beyond EtOH's positive reinforcing effects, is it possible that the antianxiety properties of the drug also participate in the structure of early EtOH-related memories? Antianxiety effects of $\mathrm{EtOH}$ have been observed in infant rats. Ultrasonic vocalizations caused by the stress of isolation or derived from a given forced administration procedure (e.g., intraperitoneal, intracisternal or intragastrical) significantly decrease when delivering low to moderate EtOH doses (Pautassi et al., 2007, 2012). Infantile aversive conditioned responses have also been observed to decrease, whenever EtOH is paired with the aversive US; a learning process known as devaluation (Pautassi et al., 2006). Both phenomena argue in favor of early sensitivity to the drug's antianxiety effects which are similar to those observed when using a GABA-A receptor agonist such as midazolam (Pautassi et al., 2007). Despite these considerations, the involvement of EtOH's antianxiety properties has not been directly assessed during prenatal or early postnatal life.

Recent studies performed during the stage equivalent to the 3rd human gestational trimester have suggested the implication of EtOH's antianxiety effects in associative learning processes. The studies have been conducted during postnatal days 3, 5, and 7 in the rat and they were principally aimed at analyzing EtOH's effects upon neurorespiratory plasticity. During this and earlier stages in development, the immature organism learns an association between different ambient cues and the drug's depressant effects upon respiration (Cullere et al., 2015; Macchione et al., 2016). We also observed that stressors like maternal deprivation, exposure to a novel context and intragastric or intracisternal administrations had a major disruptive impact upon breathing patterns (Acevedo et al., 2017; Macchione et al., 2018). Recently, utilizing a tactile discrimination procedure we found that intragastric administration of a vehicle solution in maternally deprived pups generated a significant increase in the level of apneic episodes. These disruptions, probably caused by an abnormal level of arousal, were significantly attenuated when EtOH $(2.0 \mathrm{~g} / \mathrm{kg})$ rather than the vehicle was administered. In this study, 
two groups of pups were defined by either EtOH or vehicle administration paired with a salient texture across days. A third group received $\mathrm{EtOH}$ during the first 2 days of training while the third-day vehicle was administered. Pups in this last group, despite receiving a vehicle, showed similar attenuations of the apneic episodes as those always treated with the drug. This effect appears to indicate a conditioned respiratory response probably associated with the preceding experiences with the antianxiety effects of the drug. It is also important to note that those pups that were always treated with vehicle later exhibited very low levels of preference towards the tactile cue associated with the administration procedure. This apparent conditioned aversion was completely absent in pups previously exposed to the drug (D'Aloisio et al., 2019). Given these results, it can be argued that fetal alcohol programming leading to subsequent EtOH affinity implies the interaction between two non-mutually exclusive motivational properties of the drug: it's positive as well as its antianxiety effects.

To our knowledge, the role of ACD in the early modulation of EtOH's anxiolytic effects has not been analyzed. In adult organisms of different altricial species, this phenomenon has been, at most, scarcely analyzed. The results in adults are controversial and dependent upon dosing factors and the site of administration of the metabolite or of drugs that affect the process of EtOH metabolism. Given the marked ontogenetic changes concerning peripheral or central EtOH metabolism, it is also difficult to extrapolate what is known in adults to early ontogenetic stages. Considering this important limitation, the adult literature endorses the anxiogenic effects of the metabolite following its ingestion (Plescia et al., 2015) as well as when the metabolite is intraperitoneally administered (Escrig et al., 2012). When ACD peripheral metabolism was inhibited through cyanamide there were no indications that ACD participates in EtOH-induced anxiolytic effects (Tambour et al., 2005). Focusing on cerebral metabolism of EtOH into ACD, the inhibition of this process or the inactivation of $\mathrm{ACD}$, have a suppressive effect on the anxiolytic actions of EtOH (Correa et al., 2008). As can be observed and considering the limitations of ontogenetic comparisons, there is not enough evidence to understand the role of the metabolite relative to EtOH's anxiolytic properties.

\section{ROLE OF THE OPIOID SYSTEM IN THE MODULATION OF PRENATAL ETOH REINFORCEMENT}

EtOH induces the release of opioids (Herz, 1997; Gianoulakis, 2001) and the endogenous opioid system plays a major role in EtOH reinforcement (Méndez and Morales-Mulia, 2008). EtOH reinforcing effects are mediated mainly through the stimulation of the mu (MOR) and delta (DOR) opioid receptors (Acquas et al., 1993; Herz, 1997). In infant and adult nondependent rodents, kappa opioid receptors (KOR) appears to mediate the aversive properties of alcohol (Land et al., 2009) and may contribute to EtOH's anxiolytic effects (Walker and Koob, 2008). The NOP receptor (nociceptin/orphanin FQ peptide) also appears to be critically involved in alcohol affinity.
Pharmacological studies indicate that nociceptin and other NOP agonists are effective in reducing EtOH drinking (Martin-Fardon et al., 2010) and reinforcement (Miranda-Morales et al., 2013; Miranda-Morales et al., 2014).

Regarding the effects of prenatal EtOH exposure, general blockade of the opioid system by administration of naloxone to pregnant intoxicated rat dams inhibits the facilitative effect of prenatal EtOH exposure on subsequent EtOH reinforcement in neonates (Miranda-Morales et al., 2010), infants (Chotro and Arias, 2003; Gabriela Chotro and Arias, 2007; MirandaMorales et al., 2010) and adolescents (Chotro and Arias, 2003). Furthermore, MOR prenatal blockade completely inhibited the facilitative effect on EtOH intake and palatability, while KOR prenatal antagonism only partially reduced the palatability effect (Díaz-Cenzano et al., 2014). Nevertheless, alcohol odor attraction in neonates prenatally exposed to the drug is attenuated by mu or kappa antagonism (Youngentob et al., 2012; Gaztañaga et al., 2015). In summary, this evidence implies activation of the endogenous opioid system following fetal alcohol exposure and the involvement of opioid activity in order for $\mathrm{EtOH}$ to function as an effective positive reinforcer during early ontogeny. It is necessary to observe that these effects, as well as the ones that will later be reported, have been encountered when utilizing relatively low to moderate $\mathrm{EtOH}$ doses during late gestation. As previously stated, these levels of intoxication fail to exert morphological alterations or to significantly affect the sensory, behavioral or learning capabilities of the developing organism (Molina and Chotro, 1989b; Molina et al., 1989; Lecanuet et al., 1995). In other words, the animal studies under consideration do not meet the criteria of FAS or FASD-like phenotypes as those indicated by Petrelli et al. (2018). Beyond these considerations, it is necessary to observe that animal studies based on chronic and high $\mathrm{EtOH}$ doses during gestation have indicated severe alterations in the endorphin system that results in hyperresponsiveness to stressors, a phenomenon that may also lead to heightened EtOH consumption given the antianxiety effects of the drug (Weinberg et al., 1996; Sarkar et al., 2007).

Brief prenatal exposure to moderate EtOH doses significantly reduces opioid peptide concentrations, indicating a possible mechanism by which fetal intoxication can affect future responsiveness towards EtOH (Bordner and Deak, 2015). Other fetal-related studies also indicate selective changes in Methionine-enkephalin (MET-ENK) levels in regions of the mesocorticolimbic and nigrostriatal systems, the hypothalamus and hippocampus showing the involvement of enkephalins in EtOH reinforcement (Abate et al., 2014). MET-ENK levels are specifically changed by fetal intoxication in the abovementioned central areas during adolescence. These neural enkephalinergic changes modulate later adolescent sensitivity to different motor effects of EtOH (Abate et al., 2017). Interestingly, fetal alcohol experiences also increased levels of mu-opioid receptor transcripts after intake without affecting DOR or KOR receptor transcripts in adolescents (Fabio et al., 2015). MOR mRNA levels revealed differences in infant rats tested in terms of EtOH consumption. This effect was observed when comparing prenatally manipulated subjects (mothers administered with either EtOH or vehicle during late gestation) vs. unmanipulated 
animals. Consequently, prenatal manipulation promotes changes in MOR mRNA expression (Guttlein et al., 2019). In this study, MOR mRNA levels increased in infant rats following the consumption of the drug. Moreover, prenatal intragastric manipulation during late pregnancy (that can act as a mild stressor) inhibited the increment of MOR mRNA when pups were tested in an EtOH intake test (Guttlein et al., 2019). These studies suggest a key role of MOR and the enkephalinergic systems in EtOH-mediated reinforcement during early ontogeny. In addition, fetal alcohol experiences modulated these opioid sub-systems in terms of further responsiveness to EtOH.

The kappa opioid system is of special interest when regarding fetal alcohol exposure in part because of an established functional switch during ontogeny, from mediating appetitive during early infancy (Petrov et al., 2006) to aversive motivated behaviors (Shippenberg and Herz, 1986; Bals-Kubik et al., 1989). Fetal intoxication also seems to affect KOR function and expression. Infants prenatally exposed to EtOH exhibited either no aversion or appetitive responding to KOR activation, while control subjects reacted aversively following KOR activation. Furthermore, following antenatal experience with the drug, synaptosomal KOR expression was down-regulated in brain areas implicated in the motivational effects of the drug such as the nucleus accumbens, amygdala, and hippocampus (Nizhnikov et al., 2014). As previously mentioned, prenatal EtOH may trigger transient alterations in KORs during early ontogeny. These alterations mimic the levels of KOR mRNA expression in nucleus accumbens, infralimbic cortex and ventral tegmental area in adolescents prenatally exposed to the drug (Fabio et al., 2015). Bordner and Deak (Bordner and Deak, 2015) reported a similar transient result: a heightened expression of prodynorphin (PDYN, the gene coding for the pre-protein that yields dynorphins, the endogenous ligands of KOR) mRNA transcript in ventral tegmental area in rats prenatally exposed to the drug at postnatal day (PD) 4 but not at PDs 8 or 12. While the underlying mechanisms for these effects are not yet clear, it has been recently reported an increase in mRNA levels of KOR and PDYN in the ventral tegmental area of infant and adolescent rats prenatally exposed to EtOH. Epigenetic modifications seem to explain the changes in gene expression since these effects were associated with a reduction of DNA methylation at PDYN and KOR gene promoters (Wille-Bille et al., 2018). Alternative studies also showed that gene expression from the hypothalamus of rat pups (unmanipulated during gestation) exhibited a down-regulated expression of PDYN mRNA and up-regulated mRNA expression of KOR when the first experience with EtOH was defined by infantile consumption of the drug (Guttlein et al., 2019). These results support the hypothesis of Walker and Koob (2008) that repeated EtOH exposure activates an anti-reward system that sensitizes the organism to stress and anxiety-related stimuli and, in turn, promotes a particular sensitivity to EtOH's anxiolytic effects.

Further research is required to investigate the interconnection between prenatal ACD and the opioid system. D'Addario et al. (2008) reported changes in the expression of the opioid receptors and the precursors of their ligands in response not only to $\mathrm{EtOH}$ but also to ACD exposure in human neuroblastoma cells.
ACD represents the possible candidate by which EtOH increases the release of $\beta$-endorphin which, in turn, can modulate the activity of other neurotransmitter systems such as mesolimbic dopamine (Font et al., 2013). In fact, it has been demonstrated that the opioid system participates in ACD-induced increments in dopaminergic neuronal activity (Fois and Diana, 2016). Specifically, opioid antagonists (naloxone and naltrexone) were found to abolish ACD-induced increase in the firing rate and bursting activity of the dopaminergic neurons of the ventral tegmental area.

The hypothesis that the interaction between ACD and the opioid system in the early regulation of $\mathrm{EtOH}$ affinity is also supported, at least indirectly, by preclinical approaches where EtOH maternal intoxication occurred during late prenatal life. As stated, this procedure results in subsequent increases in drug palatability and EtOH intake (Schaal et al., 2013); effects that are eliminated when the state of intoxication is preceded by the administration of the opioid antagonist naltrexone (Miranda-Morales et al., 2014). Interestingly, when utilizing the same animal model but, in this case, sequestering $\mathrm{ACD}$ via D-penicillamine in fetuses under the state of $\mathrm{EtOH}$ intoxication, completely eliminates later affinity for the drug (March et al., 2013c).

\section{HUMAN STUDIES ENDORSING FETAL ALCOHOL PROGRAMMING OF SUBSEQUENT ALCOHOL AFFINITY}

When considering human-based literature it is also clear that the fetus processes non-biological volatile substances present in the amniotic fluid. For example, when anise is incorporated in the maternal diet during the last 2 weeks of pregnancy, infants exhibit a stable preference for this odorant while non-exposed controls rather exhibit aversive responding (Schaal et al., 2000). There are also indications that during neonatal life the smell of the amniotic fluid is more effective in guiding nipple attachment even when compared with the natural scent of the mother's breast (Varendi et al., 2010). When considering the process of lactation, the excellent work of Mennella and Beauchamp (1991, 1993) and Mennella (1998) has demonstrated that human babies not only process minimal amounts of alcohol in maternal milk but also that this experience enhances alcohol odor preferences.

The first human study that was conducted relative to $\mathrm{EtOH}$ exposure during fetal life and later neonatal alcohol recognition and discrimination was performed in the 2,000 year (Faas et al., 2000). It is important to note that in this study none of the participants exhibited excessive $\mathrm{EtOH}$ intake patterns during pregnancy and all the neonates under evaluation (postpartum age: $24-48 \mathrm{~h}$ ) were considered as completely healthy as a function of the pertinent clinical and biochemical analyses. Mothers were classified as infrequent or moderate drinkers. This last group was constrained to mothers that drank at least once a week and their consumption scores per occasion averaged approximately $22 \mathrm{~g}$ of 190 proof alcohol. Newborns were sequentially stimulated with a cotton 
swab placed close to the nostrils containing $0.16 \mathrm{~g}$ of alcohol or a similar amount of a novel scent (lemon). Head and body movements were video recorded. No differences emerged when contrasting motor activity patterns elicited by lemon odor as a function of maternal alcohol drinking patterns. When employing alcohol odor, babies born to moderate drinkers displayed heightened body, head and facial movements. Subsequently, a new study was conducted using similar experimental procedures and criteria but in this case, the Neonatal Facial Action Coding system was employed (Faas et al., 2015). Facial expressions indicative of appetitive (suckling, smiling and tongue protrusion) or aversive (gaping, brow and nose wrinkling and eye blinking) facial expressions were recorded by blind experimenters. When stimulated with alcohol odor, newborns delivered by moderate drinkers exhibited significantly higher frequencies of appetitive facial responsiveness (particularly when considering tongue protrusion) when compared to babies representative of abstemious or infrequent drinkers. From a correlational perspective the overall amount of alcohol consumed during pregnancy positively and significantly correlated with appetitive reactivity. These results have been recently validated and extended in a clinical investigation where binge drinkers during pregnancy were also included (Anunziata et al., 2019 under revision). Babies born to these mothers were the ones exhibiting the highest levels of appetitive facial expressions, coupled with diminished aversive responding when confronted with alcohol odor. Once again, differential patterns of alcohol use during pregnancy had no effect when newborns were exposed to a novel scent. In summary, moderate or relatively high levels of alcohol intake during pregnancy promote EtOH odor recognition, discrimination and heightened hedonic responses in human newborns.

Does preference for EtOH's sensory attributes as a function of prenatal exposure to the drug persists in subsequent human ontogenetic stages? The first observation that appears pertinent is that 6-16-year-old children or adolescents heavily exposed to alcohol in utero (at least four drinks per occasion at least once a week or 14 drinks per week during gestation) exhibit poor performance in the San Diego Odor Identification Test. None of these subjects was diagnosed with FAS and interestingly, the evaluation did not include EtOH odor (Bower et al., 2013). Despite these olfactory deficits derived from $\mathrm{EtOH}$ intrauterine exposure, young adults (18-19 years old) born to mothers that drank at least two standards drinks per day during pregnancy, exhibit heightened relative ratings of pleasantness for alcohol odors (Hannigan et al., 2015). More specifically, higher levels of prenatal alcohol exposure were related to higher ratings of pleasantness for the scent of the drug. The importance of this result is highlighted when considering several factors systematically controlled by the authors of the study. Among others, the study is characterized by detailed information relative to maternal drinking patterns based on beverage type, specific drinking habits, binge drinking episodes, number of standard drinks at particular times of the day and days of the week when the drug was consumed. Participants (young adults with differential levels of prenatal EtOH exposure) were assessed in terms of current risk alcohol use while other control variables were also taken into account (e.g.,: home environment, parenting quality, maternal age at the time of the first prenatal visit, IQ, education, and prenatal exposure to other drugs of abuse such as nicotine, marijuana, and cocaine). When considering the olfactory assessment procedures, participants were evaluated using the "Bottle Test" based on studies performed by Schmidt and Beauchamp (1988) and Mennella and Garcia (2000) which allows the evaluation of olfactory identification in conjunction with the possibility of determining levels of pleasantness elicited by a given odor stimulus. The University of Pennsylvania Smell Identification Test (Doty et al., 1984a,b, 1989; Doty and Agrawal, 1989) was also employed to control possible olfactory dysfunctions as anosmia or mild, moderate, or severe smell loss. The main finding related to the significant association existing between prenatal alcohol exposure and alcohol odor preference endorses the hypothesis of prenatally acquired memories that are retained for long periods of time despite a considerable number of interceding postnatal experiences.

From an epidemiological perspective, approximately a decade ago, Foltran et al. (2011) systemically reviewed the literature linking prenatal maternal drinking and alcohol use and abuse during postnatal life. Seven studies were taken into account; two of them were conducted in Australia (Alati et al., 2006, 2008a,b) while the remaining investigations were performed in the USA (Baer et al., 1998, 2003; Griesler and Kandel, 1998; Yates et al., 1998; Barr et al., 2006). All of these studies with the exception of the one conducted by Yates et al. (1998; case-control investigation) were based on prospective cohort analysis. Evaluations relative to $\mathrm{EtOH}$ affinity focused on different dependent variables; among others, children's drinking patterns at age 14 and onset of alcohol disorders during adolescence and young adulthood. Different covariates were taken into account (e.g., family and maternal history of psychopathological disorders, prenatal consumption of other drugs of abuse, socioeconomic and educational as well as different developmental parameters at birth and during the childhood of the participants under evaluation). As explicitly mentioned in Foltran's review (Foltran et al., 2011) the overall results of these epidemiological studies “... seem to provide support for a biological origin of some cases of early drinking through a 'programming' effect on the brain's natural reward circuitry. They confirm emerging evidence pointing to in utero alcohol exposure, at least at high doses, in the development of addictions."

Recent epidemiological studies have also strengthened the hypothesis stating that intrauterine $\mathrm{EtOH}$ exposure leads to later alcohol use and abuse. In a prospective longitudinal study conducted by Goldschmidt et al. (2019), offspring were evaluated from birth to young adulthood as a function of maternal consumption during the 1st, 2nd and/or 3rd trimester of pregnancy. Relative to higher levels of drinking and Alcohol Use Disorders by age 22, the study concludes that prenatal exposure to even one drink per day significantly augments these problematic consequences. In Sweeden, it has also been observed that individuals diagnosed with FAS are more likely to be hospitalized for alcohol abuse disorders (9\% vs. $2 \%$ 
corresponding to healthy control subjects; Rangmar et al., 2015). In a sample of a low-income African-American population in the USA, there have also been indications that prenatal alcohol exposure, especially in young adult males, leads not only to legal difficulties but also to heightened alcohol use. In this study, higher levels of alcohol use were encountered in prenatally exposed subjects that do not exhibit physical or cognitive deficits. When contrasting these results with those reported for example by Rangmar et al. (2015), it appears that alcohol drinking patterns and alcohol use disorders dependent upon gestational exposure to the drug are also modulated by different intervening variables. Ethnicity, alcoholism's genetic predisposition, socioeconomic and educational status, sensitivity to EtOH's disruptive effects upon externalizing traits (e.g., low shyness, hyperactivity, attention deficits and conduct problems in childhood and early adolescence) should not be dismissed when determining alcohol use and abuse disorders in fetuses exposed to the drug (Kendler et al., 2013).

In agreement with Foltran et al. (2011), the human literature is congruent with those preclinical studies previously described relative to the concept of fetal alcohol programming of subsequent alcohol affinity. In prior sections, we have emphasized functional sensory and learning capabilities (sensitization to EtOH's motivational effects and associative learning processes) of the unborn organism that generate specific alcohol-related memories. These processes in no way exclude alternative or complementary mechanisms that may also intervene in the early generation of alcohol programming. One of these mechanisms is related to the dysregulation of the hypothalamic-pituitary-adrenal axis of animals and humans prenatally exposed to the drug (Hellemans et al., 2010) that eventually leads to anxiety, depression, conduct disorders and emotional disorders (Easey et al., 2019). The comorbidity between these disorders and alcohol use and abuse is well known (Kingston et al., 2017; Oliveira et al., 2018).

\section{CONCLUDING REMARKS}

The present review focuses on the functional capabilities of the unborn organism that are recruited following alcohol maternal consumption. Both, the animal and human literature consistently demonstrate that fetuses acquire information of EtOH's chemosensory attributes even when minimal amounts of the drug stimulate olfactory or gustatory receptors. Prenatal exposure to moderate or even high $\mathrm{EtOH}$ doses has also been observed to sensitize the organism to the drug's motivational properties; particularly its positive reinforcing effects or its

\section{REFERENCES}

Abate, P., Hernández-Fonseca, K., Reyes-Guzmán, A. C., Barbosa-Luna, I. G., and Méndez, M. (2014). Prenatal ethanol exposure alters met-enkephalin expression in brain regions related with reinforcement: possible mechanism for ethanol consumption in offspring. Behav. Brain Res. 274, 194-204. doi: 10.1016/j.bbr.2014.08.022 anxiolytic effects modulated by the endogenous opiate system. The central accumulation of EtOH or of its principal metabolite (ACD) exert unconditioned motivational effects that are rapidly associated with the drug's sensory cues leading to long-lasting memories that impact upon later alcohol affinity even in terms of generating patterns of drug abuse. As discussed, the process of Fetal Alcohol Programming might occur independently from the teratological effects of the drug.

Fetal Alcohol Programming should broaden our knowledge of potential alterations that are still not taken into account in the diagnostic criteria of FASD. Behavioral signs of Fetal Alcohol Programming have been already detected through relatively simple neonatal techniques developed for altricial mammals including humans (Abate et al., 2008; Faas et al., 2015). These considerations coupled with the ample range of physical, behavioral and cognitive deficits caused by intrauterine EtOH exposure should emphasize the urgent need for more profound and ample primary prevention strategies of the consequences of fetal alcohol exposure. This last statement is even more relevant when considering at least three factors: (i) Internationally, approximately $10 \%$ of women consume alcohol while pregnant. One of every 67 of these women delivers a child diagnosed with FAS (Popova et al., 2017); (ii) fertile adolescents and young adults constitute a population segment particularly vulnerable when considering alcohol use and abuse that increases the risk of delivering a child with FASD or programmed in terms of alcohol affinity; and (iii) Re-exposure to the drug during lactation or subsequent stages in development (childhood or adolescence) also constitutes a risk factor in terms of potentiating the imprinting-like phenomenon here referred as Fetal Alcohol Programming [lactation: (Pepino and Mennella, 2004); (Pueta et al., 2008); infants: (Culleré et al., 2014); adolescents: (Eade and Youngentob, 2010)].

\section{AUTHOR CONTRIBUTIONS}

JM, RM-M, and PA conceptualized and designed the revision and drafted the sequential versions of the manuscript. GD'A and FA participated in the writing process of the revision as well as in the appropriate selection of the studies under examination.

\section{FUNDING}

This work was supported by grants from Secretaría de Ciencia y Técnica, Universidad Nacional de Córdoba (SECyT; 2017-2018) and Secretaría de Políticas Integrales sobre Drogas de la Nación Argentina (SEDRONAR 2018-2019) awarded to JM.

Abate, P., Pepino, M. Y., Domínguez, H. D., Spear, N. E., and Molina, J. C. (2000) Fetal associative learning mediated through maternal alcohol intoxication. Alcohol. Clin. Exp. Res. 24, 39-47. doi: 10.1111/j.1530-0277.2000.tb04551.x

Abate, P., Pueta, M., Spear, N. E., and Molina, J. C. (2008). Fetal learning about ethanol and later ethanol responsiveness: evidence against "safe" amounts of prenatal exposure. Exp. Biol. Med. 233, 139-154. doi: 10.3181/07 03-mr-69 
Abate, P., Reyes-Guzmán, A. C., Hernández-Fonseca, K., and Méndez, M. (2017). Prenatal ethanol exposure modifies locomotor activity and induces selective changes in Met-enk expression in adolescent rats. Neuropeptides 62, 45-56. doi: 10.1016/j.npep.2016.11.006

Abate, P., Varlinskaya, E. I., Cheslock, S. J., Spear, N. E., and Molina, J. C. (2002). Neonatal activation of alcohol-related prenatal memories: impact on the first suckling response. Alcohol. Clin. Exp. Res. 26, 1512-1522. doi: 10.1097/01.ALC. $0000034668.93601 .8 \mathrm{~F}$

Acevedo, M. B., Macchione, A. F., Anunziata, F., Haymal, O. B., and Molina, J. C. (2017). Neonatal experiences with ethanol intoxication modify respiratory and thermoregulatory plasticity and affect subsequent ethanol intake in rats. Dev. Psychobiol. 59, 48-59. doi: 10.1002/dev.21466

Acquas, E., Meloni, M., and Di Chiara, G. (1993). Blockade of $\delta$-opioid receptors in the nucleus accumbens prevents ethanol-induced stimulation of dopamine release. Eur. J. Pharmacol. 230, 239-241. doi: 10.1016/0014-2999(93) 90809-v

Al Aïn, S., Belin, L., Schaal, B., and Patris, B. (2013). How does a newly born mouse get to the nipple? Odor substrates eliciting first nipple grasping and sucking responses. Dev. Psychobiol. 55, 888-901. doi: 10.1002/dev.21082

Alati, R., Al Mamun, A., Williams, G. M., O'Callaghan, M., Najman, J. M., and Bor, W. (2006). In utero alcohol exposure and prediction of alcohol disorders in early adulthood: a birth cohort study. Arch. Gen. Psychiatry 63, 1009-1016. doi: 10.1001/archpsyc.63.9.1009

Alati, R., Clavarino, A., Najman, J. M., O’Callaghan, M., Bor, W., Mamun, A. A., et al. (2008a). The developmental origin of adolescent alcohol use: findings from the Mater University Study of Pregnancy and its outcomes. Drug Alcohol Depend. 98, 136-143. doi: 10.1016/j.drugalcdep.2008.05.011

Alati, R., Macleod, J., Hickman, M., Sayal, K., May, M., Smith, G. D., et al. (2008b). Intrauterine exposure to alcohol and tobacco use and childhood IQ: findings from a parental-offspring comparison within the avon longitudinal study of parents and children. Pediatr. Res. 64, 659-666. doi: 10.1203/pdr. $0 \mathrm{~b} 013 \mathrm{e} 318187 \mathrm{cc} 31$

Arias, C., and Chotro, M. G. (2006). Ethanol-induced preferences or aversions as a function of age in preweanling rats. Behav. Neurosci. 120, 710-718. doi: 10.1037/0735-7044.120.3.710

Arias, C., Spear, N. E., Molina, J. C., Molina, A., and Molina, J. C. (2007). Rapid acquisition of operant conditioning in 5-day-old rat pups: a new technique articulating suckling-related motor activity and milk reinforcement. Dev. Psychobiol. 49, 576-588. doi: 10.1002/dev.20236

Bachmanov, A. A., Kiefer, S. W., Molina, J. C., Tordoff, M. G., Duffy, V. B., Bartoshuk, L. M., et al. (2003). Chemosensory factors influencing alcohol perception, preferences, and consumption. Alcohol. Clin. Exp. Res. 27, 220-231. doi: 10.1097/01.ALC.0000051021.99641.19

Baer, J. S., Barr, H. M., Bookstein, F. L., Sampson, P. D., and Streissguth, A. P. (1998). Prenatal alcohol exposure and family history of alcoholism in the etiology of adolescent alcohol problems. J. Stud. Alcohol 59, 533-543. doi: 10.15288/jsa.1998.59.533

Baer, J. S., Sampson, P. D., Barr, H. M., Connor, P. D., and Streissguth, A. P. (2003). A 21-year longitudinal analysis of the effects of prenatal alcohol exposure on young adult drinking. Arch. Gen. Psychiatry 60, 377-385. doi: 10.1001/archpsyc.60.4.377

Bals-Kubik, R., Herz, A., and Shippenberg, T. S. (1989). Evidence that the aversive effects of opioid antagonists and $\kappa$-agonists are centrally mediated. Psychopharmacology 98, 203-206. doi: 10.1007/bf00444692

Barker, D. J. P., Osmond, C., Kajantie, E., and Eriksson, J. G. (2009). Growth and chronic disease: findings in the helsinki birth cohort. Ann. Hum. Biol. 36, 444-458. doi: 10.1080/03014460902980295

Barr, H. M., Bookstein, F. L., O’Malley, K. D., Connor, P. D., Huggins, J. E., and Streissguth, A. P. (2006). Binge drinking during pregnancy as a predictor of psychiatric disorders on the structured clinical interview for DSM-IV in young adult offspring. Am. J. Psychiatry 163, 1061-1065. doi: 10.1176/ajp.2006.163. 6.1061

Beauchamp, G. K., and Mennella, J. A. (2011). Flavor perception in human infants: development and functional significance. Digestion 83, 1-6. doi: 10.1159/000323397

Bloomfield, F., Alexander, T., Muelbert, M., and Beker, F. (2017). Smell and taste in the preterm infant. Early Hum. Dev. 114, 31-34. doi: 10.1016/j.earlhumdev. 2017.09.012
Bond, N. W., and Di Giusto, E. L. (1976). Effects of prenatal alcohol consumption on open-field behaviour and alcohol preference in rats. Psychopharmacologia 46, 163-165. doi: 10.1007/bf00421386

Bordner, K., and Deak, T. (2015). Endogenous opioids as substrates for ethanol intake in the neonatal rat: the impact of prenatal ethanol exposure on the opioid family in the early postnatal period. Physiol. Behav. 148, 100-110. doi: 10.1016/j.physbeh.2015.02.013

Bordner, K. A., Molina, J. C., and Spear, N. E. (2008). Analysis of ethanol reinforcement in 1-day-old rats: assessment through a brief and novel operant procedure. Alcohol. Clin. Exp. Res. 32, 580-592. doi: 10.1111/j.1530-0277.2007. 00609.x

Bower, E., Szajer, J., Mattson, S. N., Riley, E. P., and Murphy, C. (2013). Impaired odor identification in children with histories of heavy prenatal alcohol exposure. Alcohol 47, 275-278. doi: 10.1016/j.alcohol.2013. 03.002

Calkins, K., and Devaskar, S. U. (2011). Fetal origins of adult disease. Curr. Probl. Pediatr. Adolesc. Health Care. 41, 158-176. doi: 10.1016/j.cppeds.2011.01.001

Cernoch, J. M., and Porter, R. H. (1985). Recognition of maternal axillary odors by infants. Child Dev. 56, 1593-1598. doi: 10.2307/1130478

Çevik, M. Ö. (2014). Habituation, sensitization, and Pavlovian conditioning. Front. Integr. Neurosci. 8:13. doi: 10.3389/fnint.2014.00013

Cheslock, S. J., Varlinskaya, E. I., Petrov, E. S., Silveri, M. M., Spear, L. P., and Spear, N. E. (2001). Ethanol as a reinforcer in the newborn's first suckling experience. Alcohol. Clin. Exp. Res. 25, 391-402. doi: 10.1097/00000374200103000-00011

Chotro, M. G., Arias, C., and Laviola, G. (2007). Increased ethanol intake after prenatal ethanol exposure: studies with animals. Neurosci. Biobehav. Rev. 31, 181-191. doi: 10.1016/j.neubiorev.2006.06.021

Chotro, M. G., Arias, C., and Spear, N. E. (2009). Binge ethanol exposure in late gestation induces ethanol aversion in the dam but enhances ethanol intake in the offspring and affects their postnatal learning about ethanol. Alcohol 43, 453-463. doi: 10.1016/j.alcohol.2009.08.001

Chotro, M., and Arias, C. (2003). Prenatal exposure to ethanol increases ethanol consumption: a conditioned response? Alcohol 30, 19-28. doi: 10.1016/s07418329(03)00037-5

Chotro, M. G., Córdoba, N. E., and Molina, J. C. (1991). Acute prenatal experience with alcohol in the amniotic fluid: interactions with aversive and appetitive alcohol orosensory learning in the rat pup. Dev. Psychobiol. 24, 431-451. doi: 10.1002/dev.420240605

Chotro, M. G., and Molina, J. C. (1990). Acute ethanol contamination of the amniotic fluid during gestational day 21: postnatal changes in alcohol responsiveness in rats. Dev. Psychobiol. 23, 535-547. doi: 10.1002/dev. 420230608

Chotro, M. G., and Molina, J. C. (1992). Bradycardiac responses elicited by alcohol odor in rat neonates: influence of In utero experience with ethanol. Psychopharmacology 106, 491-496. doi: 10.1007/bf02244820

Clark-Gambelunghe, M. B., and Clark, D. A. (2015). Sensory development. Pediatr. Clin. North Am. 62, 367-384. doi: 10.1016/j.pcl.2014.11.003

Corona, R., and Lévy, F. (2015). Chemical olfactory signals and parenthood in mammals. Horm. Behav. 68, 77-90. doi: 10.1016/j.yhbeh.2014.06.018

Correa, M., Manrique, H. M., Font, L., Escrig, M. A., and Aragon, C. M. G. (2008). Reduction in the anxiolytic effects of ethanol by centrally formed acetaldehyde: the role of catalase inhibitors and acetaldehyde-sequestering agents. Psychopharmacology 200, 455-464. doi: 10.1007/s00213-0081219-3

Correa, M., Sanchis-Segura, C., and Aragon, C. M. (2001). Brain catalase activity is highly correlated with ethanol-induced locomotor activity in mice. Physiol. Behav. 73, 641-647. doi: 10.1016/s0031-9384(01)00511-x

Cullere, M., Macchione, A. F., Haymal, B., Paradelo, M., Langer, M. D., Spear, N. E., et al. (2015). Neonatal sensitization to ethanol-induced breathing disruptions as a function of late prenatal exposure to the drug in the rat: modulatory effects of ethanol's chemosensory cues. Physiol. Behav. 139, 412-422. doi: 10.1016/j.physbeh.2014.10.017

Culleré, M. E., Spear, N. E., and Molina, J. C. (2014). Prenatal ethanol increases sucrose reinforcement, an effect strengthened by postnatal association of ethanol and sucrose. Alcohol 48, 25-33. doi: 10.1016/j.alcohol.2013.11.003

Cunningham, C. L., Fidler, T. L., and Hill, K. G. (2000). Animal models of alcohol's motivational effects. Alcohol Res. Health 24, 85-92. 
Díaz-Cenzano, E., and Chotro, M. G. (2010). Prenatal binge ethanol exposure on gestation days 19-20, but not on days 17-18, increases postnatal ethanol acceptance in rats. Behav. Neurosci. 124, 362-369. doi: 10.1037/a0019482

Díaz-Cenzano, E., Gaztañaga, M., and Gabriela Chotro, M. (2014). Exposure to ethanol on prenatal days 19-20 increases ethanol intake and palatability in the infant rat: involvement of kappa and mu opioid receptors. Dev. Psychobiol. 56, 1167-1178. doi: 10.1002/dev.21162

Díaz-Marte, C., Gutiérrez-García, A. G., Mendoza-López, M. R., and Contreras, C. M. (2010). Recién nacidos despliegan movimientos de orientación hacia su líquido amniótico y algunos ácidos grasos. Rev. Med. 10, 6-10.

D’Addario, C., Ming, Y., Ögren, S. O., and Terenius, L. (2008). The role of acetaldehyde in mediating effects of alcohol on expression of endogenous opioid system genes in a neuroblastoma cell line. FASEB J. 22, 662-670. doi: 10.1096/fj.07-8346com

D'Aloisio, G., Acevedo, M. B., Macchione, A. F., Anunziata, F., and Molina, J. C. (2019). Co-existence of ethanol-related respiratory and motivational learning processes based on a tactile discrimination procedure in neonatal rats. Alcohol doi: 10.1016/j.alcohol.2019.11.001 [Epub ahead of print].

Debiec, J., and Sullivan, R. M. (2017). The neurobiology of safety and threat learning in infancy. Neurobiol. Learn. Mem. 143, 49-58. doi: 10.1016/j.nlm. 2016.10.015

Del Maestro, R., and McDonald, W. (1987). Distribution of superoxide dismutase, glutathione peroxidase and catalase in developing rat brain. Mech. Ageing Dev. 41, 29-38. doi: 10.1016/0047-6374(87)90051-0

Di Lorenzo, P. M., Kiefer, S. W., Rice, A. G., and Garcia, J. (1986). Neural and behavioral responsivity to ethyl alcohol as a tastant. Alcohol 3, 55-61. doi: 10.1016/0741-8329(86)90071-6

Diana, M., Peana, A. T., Sirca, D., Lintas, A., Melis, M., and Enrico, P. (2008). "Crucial role of acetaldehyde in alcohol activation of the mesolimbic dopamine system. Ann. N. Y. Acad. Sci. 11, 307-317. doi: 10.1196/annals.1432.009

Dobbing, J., and Sands, J. (1979). Comparative aspects of the brain growth spurt. Early Hum. Dev. 3, 79-83. doi: 10.1016/0378-3782(79) 90022-7

Dominguez, H. D., Bocco, G., Chotro, M. G., Spear, N. E., and Molina, J. C. (1993). Operant responding controlled by milk or milk contaminated with alcohol as positive reinforcers in infant rats. Pharmacol. Biochem. Behav. 44, 403-409. doi: 10.1016/0091-3057(93)90482-9

Domínguez, H. D., López, M. F., Chotro, M. G., and Molina, J. C. (1996). Perinatal responsiveness to alcohol's chemosensory cues as a function of prenatal alcohol administration during gestational days 17-20 in the rat. Neurobiol. Learn. Mem. 65, 103-112. doi: 10.1006/nlme.1996.0012

Domínguez, H. D., López, M. F., and Molina, J. C. (1998). Neonatal responsiveness to alcohol odor and infant alcohol intake as a function of alcohol experience during late gestation. Alcohol 16, 109-117. doi: 10.1016/s0741-8329(97) 00169-9

Doty, R. L., and Agrawal, U. (1989). The shelf life of the University Of Pennsylvania smell identification test (UPSIT). Laryngoscope 99, 402-404. doi: 10.1288/00005537-198904000-00008

Doty, R. L., Frye, R. E., and Agrawal, U. (1989). Internal consistency reliability of the fractionated and whole University of Pennsylvania Smell Identification Test. Percept. Psychophys. 45, 381-384. doi: 10.3758/bf03210709

Doty, R. L., Shaman, P., and Dann, M. (1984a). Development of the university of pennsylvania smell identification test: a standardized microencapsulated test of olfactory function. Physiol. Behav. 32, 489-502. doi: 10.1016/00319384(84)90269-5

Doty, R. L., Shaman, P., Kimmelman, C. P., and Dann, M. S. (1984b). University of pennsylvania smell identification test: a rapid quantitative olfactory function test for the clinic. Laryngoscope 94, 176-178. doi: 10.1288/00005537198402000-00004

Eade, A. M., Sheehe, P. R., and Youngentob, S. L. (2010). Ontogeny of the enhanced fetal-ethanol-induced behavioral and neurophysiologic olfactory response to ethanol odor. Alcohol. Clin. Exp. Res. 34, 206-213. doi: 10.1111/j. 1530-0277.2009.01083.x

Eade, A. M., Youngentob, L. M., and Youngentob, S. L. (2016). The Interaction of ethanol ingestion and social interaction with an intoxicated peer on the odor-mediated response to the drug in adolescent rats. Alcohol. Clin. Exp. Res. 40, 734-742. doi: 10.1111/acer.13009
Eade, A. M., and Youngentob, S. L. (2009). Adolescent ethanol experience alters immediate and long-term behavioral responses to ethanol odor in observer and demonstrator rats. Behav. Brain Funct. 5:23. doi: 10.1186/1744-9081-5-23

Eade, A. M., and Youngentob, S. L. (2010). The interaction of gestational and postnatal ethanol experience on the adolescent and adult odor-mediated responses to ethanol in observer and demonstrator rats. Alcohol. Clin. Exp. Res. 34, 1705-1713. doi: 10.1111/j.1530-0277.2010.01257.x

Easey, K. E., Dyer, M. L., Timpson, N. J., and Munafò, M. R. (2019). Prenatal alcohol exposure and offspring mental health: a systematic review. Drug Alcohol Depend. 197, 344-353. doi: 10.1016/j.drugalcdep.2019.01.007

Escarabajal, M. D., De Witte, P., and Quertemont, E. (2003). Role of acetaldehyde in ethanol-induced conditioned taste aversion in rats. Psychopharmacology 167, 130-136. doi: 10.1007/s00213-003-1427-9

Escrig, M. A., Pardo, M., Aragon, C. M., and Correa, M. (2012). Anxiogenic and stress-inducing effects of peripherally administered acetaldehyde in mice: similarities with the disulfiram-ethanol reaction. Pharmacol. Biochem. Behav. 100, 404-412. doi: 10.1016/j.pbb.2011.10.002

Faas, A. E., March, S. M., Moya, P. R., and Molina, J. C. (2015). Alcohol odor elicits appetitive facial expressions in human neonates prenatally exposed to the drug. Physiol. Behav. 148, 78-86. doi: 10.1016/j.physbeh.2015.02.031

Faas, A. E., Spontón, E. D., Moya, P. R., and Molina, J. C. (2000). Differential responsiveness to alcohol odor in human neonates Effects of maternal consumption during gestation. Alcohol 22, 7-17. doi: 10.1016/s07418329(00)00103-8

Fabio, M. C., Macchione, A. F., Nizhnikov, M. E., and Pautassi, R. M. (2015). Prenatal ethanol increases ethanol intake throughout adolescence, alters ethanol-mediated aversive learning, and affects $\mu$ but not $\delta$ or $\kappa$ opioid receptor mRNA expression. Eur. J. Neurosci. 41, 1569-1579. doi: 10.1111/ejn.12913

Fabio, M. C., March, S. M., Molina, J. C., Nizhnikov, M. E., Spear, N. E., and Pautassi, R. M. (2013). Prenatal ethanol exposure increases ethanol intake and reduces $\mathrm{C}$-fos expression in infralimbic cortex of adolescent rats. Pharmacol. Biochem. Behav. 103, 842-852. doi: 10.1016/j.pbb.2012.12.009

Fernández-Vidal, J. M., and Molina, J. C. (2004). Socially mediated alcohol preferences in adolescent rats following interactions with an intoxicated peer. Pharmacol. Biochem. Behav. 79, 229-241. doi: 10.1016/j.pbb.2004.07.010

Fois, G. R., and Diana, M. (2016). Opioid antagonists block acetaldehyde-induced increments in dopamine neurons activity. Drug Alcohol Depend. 158, 172-176. doi: 10.1016/j.drugalcdep.2015.11.013

Foltran, F., Gregori, D., Franchin, L., Verduci, E., and Giovannini, M. (2011). Effect of alcohol consumption in prenatal life, childhood, and adolescence on child development. Nutr. Rev. 69, 642-659. doi: 10.1111/j.1753-4887.2011. 00417.x

Font, L., Luján, M. Á, and Pastor, R. (2013). Involvement of the endogenous opioid system in the psychopharmacological actions of ethanol: the role of acetaldehyde. Front. Behav. Neurosci. 7:93. doi: 10.3389/fnbeh.2013.00093

Forestell, C. A., and Mennella, J. A. (2017). The relationship between infant facial expressions and food acceptance. Curr. Nutr. Rep. 6, 141-147. doi: 10.1007/s13668-017-0205-y

Fulgione, D., Trapanese, M., Buglione, M., Rippa, D., Polese, G., Maresca, V., et al. (2017). Pre-birth sense of smell in the wild boar: the ontogeny of the olfactory mucosa. Zoology 123, 11-15. doi: 10.1016/j.zool.2017.05.003

Gabriela Chotro, M., and Arias, C. (2007). Ontogenetic difference in ethanol reinforcing properties: the role of the opioid system. Behav. Pharmacol. 18, 661-666. doi: 10.1097/fbp.0b013e3282f00754

Gaztañaga, M., Angulo-Alcalde, A., Spear, N. E., and Chotro, M. G. (2017). The role of acetaldehyde in the increased acceptance of ethanol after prenatal ethanol exposure. Front. Behav. Neurosci. 11:14. doi: 10.3389/fnbeh.2017.00014

Gaztañaga, M., Aranda-Fernández, P. E., and Chotro, M. G. (2015). Prenatal exposure to vanilla or alcohol induces crawling after these odors in the neonate rat: the role of mu and kappa opioid receptor systems. Physiol. Behav. 148, 58-64. doi: 10.1016/j.physbeh.2014.12.046

Gianoulakis, C. (2001). Influence of the endogenous opioid system on high alcohol consumption and genetic predisposition to alcoholism. J. Psychiatry Neurosci. 26, 304-318.

Glendinning, J. I., Tang, J., Morales Allende, A. P., Bryant, B. P., Youngentob, L., and Youngentob, S. L. (2017). Fetal alcohol exposure reduces responsiveness of taste nerves and trigeminal chemosensory neurons to ethanol and its flavor components. J. Neurophysiol. 118, 1198-1209. doi: 10.1152/jn.00108.2017 
Goldschmidt, L., Richardson, G. A., De Genna, N. M., Cornelius, M. D., and Day, N. L. (2019). Prenatal alcohol exposure and offspring alcohol use and misuse at 22-years of age: a prospective longitudinal study. Neurotoxicol. Teratol. 71, 1-5. doi: 10.1016/j.ntt.2018.11.001

Griesler, P. C., and Kandel, D. B. (1998). The impact of maternal drinking during and after pregnancy on the drinking of adolescent offspring. J. Stud. Alcohol 59, 292-304. doi: 10.15288/jsa.1998.59.292

Guttlein, L., Macchione, A. F., Hernández-Fonseca, K., Haymal, O. B., Molina, J. C., Méndez Ubach, M., et al. (2019). Maternal manipulation during late gestation (GDs 17-20) enhances ethanol consumption and promotes changes and opioid mRNA expression in infant rats. Behav. Brain Res. 368:111908. doi: 10.1016/j.bbr.2019.111908

Hannigan, J. H., Chiodo, L. M., Sokol, R. J., Janisse, J., and Delaney-Black, V. (2015). Prenatal alcohol exposure selectively enhances young adult perceived pleasantness of alcohol odors. Physiol. Behav. 148, 71-77. doi: 10.1016/j. physbeh.2015.01.019

Hay, W. W.Jr. (2009). American Pediatric Society presidential address 2008: research in early life - benefit and promise. Pediatr. Res. 65, 117-122. doi: 10.1203/pdr.0b013e31818c7feb

Hayashi, M., Shimazaki, Y., Kamata, S., Kakiichi, N., and Ikeda, M. (1991). Disposition of ethanol and acetaldehyde in maternal blood, fetal blood and amniotic fluid of near-term pregnant rats. Bull. Environ. Contam. Toxicol. 47, 184-189. doi: 10.1007/bf01688638

Hellemans, K. G. C., Sliwowska, J. H., Verma, P., and Weinberg, J. (2010). Prenatal alcohol exposure: fetal programming and later life vulnerability to stress, depression and anxiety disorders. Neurosci. Biobehav. Rev. 34, 791-807. doi: 10.1016/j.neubiorev.2009.06.004

Hepper, P. G. (1991). Transient hypoxic episodes: a mechanism to support associative fetal learning. Anim Behav. 41, 477-480. doi: 10.1016/s00033472(05)80850-4

Hepper, P. G. (1993). In utero release from a single transient hypoxic episode: a positive reinforcer? Physiol. Behav. 53, 309-311. doi: 10.1016/00319384(93)90209-x

Herz, A. (1997). Endogenous opioid systems and alcohol addiction. Psychopharmacology 129, 99-111. doi: 10.1007/s002130050169

Israel, Y., Quintanilla, M. E., Karahanian, E., Rivera-Meza, M., and HerreraMarschitz, M. (2015). The "first hit" toward alcohol reinforcement: role of ethanol metabolites. Alcohol. Clin. Exp. Res. 39, 776-786. doi: 10.1111/acer. 12709

Jones, K. L., Smith, D. W., Ulleland, C. N., and Streissguth, A. P. (1973). Pattern of malformation in offspring of chronic alcoholic mothers. Lancet 301, 1267-1271. doi: 10.1016/s0140-6736(73)91291-9

Kelly, S. J., Bonthius, D. J., and West, J. R. (1987). Developmental changes in alcohol pharmacokinetics in rats. Alcohol. Clin. Exp. Res. 11, 281-286. doi: 10.1111/j.1530-0277.1987.tb01308.x

Kendler, K. S., Gardner, C. O., Edwards, A., Hickman, M., Heron, J., Macleod, J., et al. (2013). Dimensions of parental alcohol use/problems and offspring temperament, externalizing behaviors and alcohol use/problems. Alcohol. Clin. Exp. Res. 37, 2118-2127. doi: 10.1111/acer.12196

Kiefer, S. W. (1995). Alcohol, palatability and taste reactivity. Neurosci. Biobehav. Rev. 19, 133-141. doi: 10.1016/0149-7634(94)00027-x

Kingston, R. E. F., Marel, C., and Mills, K. L. (2017). A systematic review of the prevalence of comorbid mental health disorders in people presenting for substance use treatment in Australia. Drug Alcohol Rev. 36, 527-539. doi: 10.1111/dar. 12448

Land, B. B., Bruchas, M. R., Schattauer, S., Giardino, W. J., Aita, M., Messinger, D., et al. (2009). Activation of the kappa opioid receptor in the dorsal raphe nucleus mediates the aversive effects of stress and reinstates drug seeking. Proc. Natl. Acad. Sci. U S A 106, 19168-19173. doi: 10.1073/pnas. 0910705106

Lecanuet, J. P., Fifer, W. P., Krasnegor, N. A., and Smotherman, W. P. (1995). Fetal Development: A Psychobiological Perspective. New York, NY: Psychology Press.

Lemoine, P., Harousseau, H., Borteyru, J. P., and Menuet, J. C. (1968). Children of alcoholic parents: abnormalities observed in 127 cases. Quest Med. 8, $476-482$.

Leon, M. (1987). Plasticity of olfactory output circuits related to early olfactory learning. Trends Neurosci. 10, 434-438. doi: 10.1016/0166-2236(87) 90016-6
Méndez, M., and Morales-Mulia, M. (2008). Role of mu and delta opioid receptors in alcohol drinking behaviour. Curr. Drug Abuse Rev. 1, 239-252. doi: 10.2174/1874473710801020239

Macchione, A. F., Anunziata, F., Culleré, M. E., Haymal, B. O., Spear, N., Abate, P., et al. (2016). Conditioned breathing depression during neonatal life as a function of associating ethanol odor and the drug's intoxicating effects. Dev. Psychobiol. 58, 670-686. doi: 10.1002/dev.21398

Macchione, A. F., Anunziata, F., Haymal, B. O., Abate, P., and Molina, J. C. (2018). Brief ethanol exposure and stress-related factors disorganize neonatal breathing plasticity during the brain growth spurt period in the rat. Psychopharmacology 235, 983-998. doi: 10.1007/s00213-017-4815-2

Makin, J., and Porter, R. H. (1989). Attractiveness of lactating females' breast odors to neonates. Child Dev. 60, 803-810. doi: 10.2307/1131020

March, S. M., Abate, P., and Molina, J. C. (2013a). Acetaldehyde involvement in ethanol's postabsortive effects during early ontogeny. Front. Behav. Neurosci. 7:70. doi: 10.3389/fnbeh.2013.00070

March, S. M., Abate, P., Spear, N. E., and Molina, J. C. (2013b). The role of acetaldehyde in ethanol reinforcement assessed by Pavlovian conditioning in newborn rats. Psychopharmacology 226, 491-499. doi: 10.1007/s00213-0122920-9

March, S. M., Culleré, M. E., Abate, P., Hernández, J. I., Spear, N. E., and Molina, J. C. (2013c). Acetaldehyde reinforcement and motor reactivity in newborns with or without a prenatal history of alcohol exposure. Front. Behav. Neurosci. 7:69. doi: 10.3389/fnbeh.2013.00069

March, S. M., Pautassi, R. M., Nizhnikov, M., Fernández-Vidal, J., Spear, N. E., and Molina, J. C. (2013d). Preferencia por el olor del etanol tras la interacción social con un congénere intoxicado en ratas adolescentes expuestas a la droga In útero. Psicothema 25, 355-362.

March, S. M., Abate, P., Spear, N. E., and Molina, J. C. (2009). Fetal exposure to moderate ethanol doses: heightened operant responsiveness elicited by ethanolrelated reinforcers. Alcohol. Clin. Exp. Res. 33, 1981-1993. doi: 10.1111/j.15300277.2009.01037.x

Marlier, L., Schaal, B., and Soussignan, R. (1998). Neonatal responsiveness to the odor of amniotic and lacteal fluids: a test of perinatal chemosensory continuity. Child Dev. 69, 611-623. doi: 10.1111/j.1467-8624.1998.tb06232.x

Martin-Fardon, R., Zorrilla, E. P., Ciccocioppo, R., and Weiss, F. (2010). Role of innate and drug-induced dysregulation of brain stress and arousal systems in addiction: focus on corticotropin-releasing factor, nociceptin/orphanin FQ, and orexin/hypocretin. Brain Res. 1314, 145-161. doi: 10.1016/j.brainres.2009. 12.027

Mattson, S. N., Bernes, G. A., and Doyle, L. R. (2019). Fetal alcohol spectrum disorders: a review of the neurobehavioral deficits associated with prenatal alcohol exposure. Alcohol. Clin. Exp. Res. 43, 1046-1062. doi: 10.1111/acer. 14040

Mbiene, J. P., and Mistretta, C. M. (1997). Initial innervation of embryonic rat tongue and developing taste papillae: nerves follow distinctive and spatially restricted pathways. Acta Anat. 160, 139-158. doi: 10.1159/000 148006

Melis, M., Enrico, P., Peana, A. T., and Diana, M. (2007). Acetaldehyde mediates alcohol activation of the mesolimbic dopamine system. Eur. J. Neurosci. 26, 2824-2833. doi: 10.1111/j.1460-9568.2007.05887.x

Mennella, J. A. (1997). Infants' suckling responses to the flavor of alcohol in mothers' milk. Alcohol. Clin. Exp. Res. 21:581. doi: 10.1097/00000374199706000-00003

Mennella, J. A. (1998). Short-term effects of maternal alcohol consumption on lactational performance. Alcohol. Clin. Exp. Res. 22, 1389-1392. doi: 10.1111/j. 1530-0277.1998.tb03924.x

Mennella, J. A., and Beauchamp, G. K. (1991). The transfer of alcohol to human milk: effects on flavor and the infant's behavior. N. Engl. J. Med. 325, 981-985. doi: 10.1056/nejm199110033251401

Mennella, J. A., and Beauchamp, G. K. (1993). Beer, breast feeding, and folklore. Dev. Psychobiol. 26, 459-466. doi: 10.1002/dev.420260804

Mennella, J. A., and Garcia, P. L. (2000). Children's hedonic response to the smell of alcohol: effects of parental drinking habits. Alcohol. Clin. Exp. Res. 24, 1167-1171. doi: 10.1097/00000374-200008000-00005

Miller, M. W. (1992). Circadian rhythm of cell proliferation in the telencephalic ventricular zone: effect of in utero exposure to ethanol. Brain Res. 595, 17-24. doi: 10.1016/0006-8993(92)91447-m 
Miller, S. S., and Spear, N. E. (2009). Olfactory learning in the rat immediately after birth: unique salience of first odors. Dev. Psychobiol. 51, 488-504. doi: 10.1002/dev.20388

Miranda-Morales, R. S., Molina, J. C., Spear, N. E., and Abate, P. (2010). Participation of the endogenous opioid system in the acquisition of a prenatal ethanol-related memory: effects on neonatal and preweanling responsiveness to ethanol. Physiol. Behav. 101, 153-160. doi: 10.1016/j.physbeh.2010. 04.033

Miranda-Morales, R., Nizhnikov, M. E., and Spear, N. E. (2014). Prenatal exposure to ethanol during late gestation facilitates operant self-administration of the drug in 5-day-old rats. Alcohol 48, 19-23. doi: 10.1016/j.alcohol.2013.11.001

Miranda-Morales, R., Nizhnikov, M., Waters, D. H., and Spear, N. E. (2013). Participation of the nociceptin/orphanin FQ receptor in ethanol-mediated locomotor activation and ethanol intake in preweanling rats. Behav. Brain Res. 245, 137-144. doi: 10.1016/j.bbr.2013.02.017

Molina, J. C., and Chotro, M. G. (1989a). Acute alcohol intoxication paired with appetitive reinforcement: effects upon ethanol intake in infant rats. Behav. Neural Biol. 51, 326-345. doi: 10.1016/s0163-1047(89)90974-6

Molina, J. C., and Chotro, M. G. (1989b). Acute alcohol intoxication paired with aversive reinforcement: ethanol odor as a conditioned reinforcer in rat pups. Behav. Neural Biol. 52, 1-19. doi: 10.1016/s0163-1047(89)90122-2

Molina, J. C., Chotro, G., and Spear, N. E. (1989). Early (preweanling) recognition of alcohol's orosensory cues resulting from acute ethanol intoxication. Behav. Neural Biol. 51, 307-325. doi: 10.1016/s0163-1047(89)90961-8

Molina, J. C., Domínguez, H. D., López, M. F., Pepino, M. Y., and Faas, A. E. (1999). "The role of fetal and infantile experience with alcohol in later recognition and acceptance patterns of the drug," in Alcohol and Alcoholism: Brain and Development, eds J. H. Hanningan, N. E. Spear, L. P. Spear and C. R. Goodlett (Hillsdale, NJ: Lawrence Erlbaum Associates), 199-228.

Molina, J. C., Pautassi, R. M., Truxell, E., and Spear, N. (2007a). Differential motivational properties of ethanol during early ontogeny as a function of dose and postadministration time. Alcohol 41, 41-55. doi: 10.1016/j.alcohol.2007. 01.005

Molina, J. C., Spear, N. E., Spear, L. P., Mennella, J. A., and Lewis, M. J. (2007b). The international society for developmental psychobiology 39th annual meeting symposium: alcohol and development: beyond fetal alcohol syndrome. Dev. Psychobiol. 49, 227-242. doi: 10.1002/dev.20224

Nicolaïdis, S. (2008). Prenatal imprinting of postnatal specific appetites and feeding behavior. Metabolism 57, 22-26. doi: 10.1016/j.metabol.2008.07.004

Nizhnikov, M. E., Molina, J. C., and Spear, N. E. (2007). Central reinforcing effects of ethanol are blocked by catalase inhibition. Alcohol 41, 525-534. doi: 10.1016/j.alcohol.2007.08.006

Nizhnikov, M. E., Pautassi, R. M., Carter, J. M., Landin, J. D., Varlinskaya, E. I., Bordner, K. A., et al. (2014). Brief prenatal ethanol exposure alters behavioral sensitivity to the kappa opioid receptor agonist (U62,066E) and antagonist (Nor-BNI) and reduces kappa opioid receptor expression. Alcohol. Clin. Exp. Res. 38, 1630-1638. doi: 10.1111/acer.12416

Nizhnikov, M. E., Varlinskaya, E. I., and Spear, N. E. (2006). Reinforcing effects of central ethanol injections in newborn rat pups. Alcohol. Clin. Exp. Res. 30, 2089-2096. doi: 10.1111/j.1530-0277.2006.00253.x

Oliveira, L. M., Bermudez, M. B., Macedo, M. J. A., and Passos, I. C. (2018). Comorbid social anxiety disorder in patients with alcohol use disorder: a systematic review. J. Psychiatr. Res. 106, 8-14. doi: 10.1016/j.jpsychires.2018. 09.008

Orsini, C., Buchini, F., Piazza, P. V., Puglisi-Allegra, S., and Cabib, S. (2004). Susceptibility to amphetamine-induced place preference is predicted by locomotor response to novelty and amphetamine in the mouse. Psychopharmacology 172, 264-270. doi: 10.1007/s00213-003-1647-z

Pautassi, R. M., Nizhnikov, M. E., Fabio, M. C., and Spear, N. E. (2012). Early maternal separation affects ethanol-induced conditioning in a nor-BNI insensitive manner, but does not alter ethanol-induced locomotor activity. Pharmacol. Biochem. Behav. 100, 630-638. doi: 10.1016/j.pbb.2011.11.005

Pautassi, R. M., Nizhnikov, M., Molina, J. C., Boehm, S. L., and Spear, N. (2007). Differential effects of ethanol and midazolam upon the devaluation of an aversive memory in infant rats. Alcohol 41, 421-431. doi: 10.1016/j.alcohol. 2007.05.001

Pautassi, R. M., Nizhnikov, M. E., and Spear, N. E. (2009). Assessing appetitive, aversive and negative ethanol-mediated reinforcement through an immature rat model. Neurosci. Biobehav. Rev. 33, 953-974. doi: 10.1016/j.neubiorev.2009. 03.008

Pautassi, R. M., Sanders, S., Miller, S., Spear, N., and Molina, J. C. (2006). Early ethanol's anxiolytic effects assessed through an unconditional stimulus revaluation procedure. Alcohol. Clin. Exp. Res. 30, 448-459. doi: 10.1111/j. 1530-0277.2006.00049.x

Pautassi, R. M., Truxell, E., Molina, J. C., and Spear, N. E. (2008). Motivational effects of intraorally-infused ethanol in rat pups in an operant self-administration task. Physiol. Behav. 93, 118-129. doi: 10.1016/j.physbeh. 2007.08.004

Peana, A. T., Porcheddu, V., Bennardini, F., Carta, A., Rosas, M., and Acquas, E. (2015). Role of ethanol-derived acetaldehyde in operant oral self-administration of ethanol in rats. Psychopharmacology 232, 4269-4276. doi: 10.1007/s00213-015-4049-0

Pepino, M. Y., López, M. F., Spear, N. E., and Molina, J. C. (1999). Infant rats respond differently to alcohol after nursing from an alcohol-intoxicated dam. Alcohol 18, 189-201. doi: 10.1016/s0741-8329(99)00003-8

Pepino, M. Y., and Mennella, J. A. (2004). Advice given to women in Argentina about breast-feeding and the use of alcohol. Rev. Panam. Salud Publica 16, 408-414. doi: 10.1590/s1020-49892004001200007

Petrelli, B., Weinberg, J., and Hicks, G. G. (2018). Effects of prenatal alcohol exposure (PAE): insights into FASD using mouse models of PAE. Biochem. Cell Biol 96, 1-58. doi: 10.1139/bcb-2017-0280

Petrov, E. S., Nizhnikov, M. E., Varlinskaya, E. I., and Spear, N. E. (2006). Dynorphin A (1-13) and responsiveness of the newborn rat to a surrogate nipple: immediate behavioral consequences and reinforcement effects in conditioning. Behav. Brain Res. 170, 1-14. doi: 10.1016/j.bbr.2006.03.012

Petrov, E. S., Varlinskaya, E. I., and Spear, N. E. (2003). Reinforcement from pharmacological effects of ethanol in newborn rats. Alcohol. Clin. Exp. Res. 27, 1583-1591. doi: 10.1097/01.alc.0000089960.62640.58

Plescia, F., Brancato, A., Venniro, M., Maniaci, G., Cannizzaro, E., Sutera, F. M., et al. (2015). Acetaldehyde self-administration by a two-bottle choice paradigm: consequences on emotional reactivity, spatial learning, and memory. Alcohol 49, 139-148. doi: 10.1016/j.alcohol.2015.01.002

Popova, S., Lange, S., Probst, C., Gmel, G., and Rehm, J. (2017). Estimation of national, regional and global prevalence of alcohol use during pregnancy and fetal alcohol syndrome: a systematic review and meta-analysis. Lancet Glob. Heal. 5, e290-e299. doi: 10.1016/s2214-109x(17)30021-9

Pueta, M., Abate, P., Haymal, O. B., Spear, N. E., and Molina, J. C. (2008). Ethanol exposure during late gestation and nursing in the rat: effects upon maternal care, ethanol metabolism and infantile milk intake. Pharmacol. Biochem. Behav. 91, 21-31. doi: 10.1016/j.pbb.2008.06.007

Pueta, M., Rovasio, R. A., Abate, P., Spear, N. E., and Molina, J. C. (2011). Prenatal and postnatal ethanol experiences modulate consumption of the drug in rat pups, without impairment in the granular cell layer of the main olfactory bulb. Physiol. Behav. 102, 63-75. doi: 10.1016/j.physbeh.2010.10.009

Quertemont, E. (2004). Genetic polymorphism in ethanol metabolism: acetaldehyde contribution to alcohol abuse and alcoholism. Mol. Psychiatry 9 , 570-581. doi: 10.1038/sj.mp.4001497

Raineki, C., Pickenhagen, A., Roth, T. L., Babstock, D. M., McLean, J. H., Harley, C. W., et al. (2010). The neurobiology of infant maternal odor learning. Braz. J. Med. Biol. Res. 43, 914-919. doi: 10.1590/s0100-879x2010007500090

Rangmar, J., Sandberg, A. D., Aronson, M., and Fahlke, C. (2015). Cognitive and executive functions, social cognition and sense of coherence in adults with fetal alcohol syndrome. Nord. J. Psychiatry 69, 472-478. doi: 10.3109/08039488. 2015.1009487

Riley, E. P., Infante, M. A., and Warren, K. R. (2011). Fetal alcohol spectrum disorders: an overview. Neuropsychol. Rev. 21, 73-80. doi: 10.1007/s11065-0119166-x

Riley, E. P., and McGee, C. L. (2005). Fetal alcohol spectrum disorders: an overview with emphasis on changes in brain and behavior. Exp Biol Med. 230, 357-365. doi: 10.1177/15353702-0323006-03

Ronca, A. E., and Alberts, J. R. (1994). Sensory stimuli associated with gestation and parturition evoke cardiac and behavioral responses in fetal rats. Psychobiology 22, 270-282.

Roth, T. L., and Sullivan, R. M. (2003). Consolidation and expression of a shockinduced odor preference in rat pups is facilitated by opioids. Physiol. Behav. 78, 135-142. doi: 10.1016/s0031-9384(02)00961-7 
Roth, T. L., and Sullivan, R. M. (2006). Examining the role of endogenous opioids in learned odor-stroke associations in infant rats. Dev. Psychobiol. 48, 71-78. doi: 10.1002/dev.20107

Sanchis-Segura, C., Correa, M., Miquel, M., and Aragon, C. M. G. (2005). Catalase inhibition in the Arcuate nucleus blocks ethanol effects on the locomotor activity of rats. Neurosci. Lett. 376, 66-70. doi: 10.1016/j.neulet.2004.11.025

Sarkar, D. K., Kuhn, P., Marano, J., Chen, C., and Boyadjieva, N. (2007). Alcohol exposure during the developmental period induces $\beta$-endorphin neuronal death and causes alteration in the opioid control of stress axis function. Endocrinology 148, 2828-2834. doi: 10.1210/en.2006-1606

Schaal, B., Al Aïn, S., and Patris, B. (2013). Testing smell when it is really vital: behavioral assays of social odors in the neonatal mouse. Methods Mol. Biol. 1068, 349-371. doi: 10.1007/978-1-62703-619-1_26

Schaal, B., Hummel, T., and Soussignan, R. (2004). Olfaction in the fetal and premature infant: functional status and clinical implications. Clin. Perinatol. 31, 261-285. doi: 10.1016/j.clp.2004.04.003

Schaal, B., Marlier, L., and Soussignan, R. (2000). Human foetuses learn odours from their pregnant mother's diet. Chem. Senses 25, 729-737. doi: $10.1093 /$ chemse/25.6.729

Schaal, B., Soussignan, R., and Marlier, L. (2002). "Olfactory cognition at the start of life: the perinatal shaping of selective odor responsiveness," in Olfaction, Taste and Cognition, eds C. Rouby, B. Schaal, D. Dubois, R. Gervais and A. Holley (New York, NY: Cambridge University Press), 421-440.

Schmidt, H. J., and Beauchamp, G. K. (1988). Adult-like odor preferences and aversions in three-year-old children. Child Dev. 59, 1136-1143. doi: $10.2307 / 1130280$

Shippenberg, T. S., and Herz, A. (1986). Differential effects of mu and kappa opioid systems on motivational processes. NIDA Res. Monogr. 75, 563-566. doi: 10.1037/e471872004-001

Smotherman, W. P. (1982). Odor aversion learning by the rat fetus. Physiol. Behav. 29, 769-771. doi: 10.1016/0031-9384(82)90322-5

Spear, N. E., and Molina, J. C. (2005). Fetal or infantile exposure to ethanol promotes ethanol ingestion in adolescence and adulthood: a theoretical review. Pharmacol. Biochem. Behav. 29, 909-929. doi: 10.1097/01.alc.0000171046. 78556.66

Stickrod, G., Kimble, D. P., and Smotherman, W. P. (1982). In utero taste/odor aversion conditioning in the rat. Physiol. Behav. 28, 5-7. doi: 10.1016/00319384(82)90093-2

Sullivan, R. M., Landers, M., Yeaman, B., and Wilson, D. A. (2000). Neurophysiology: good memories of bad events in infancy. Nature 407, 38-39. doi: $10.1038 / 35024156$

Szeto, H. H. (1989). Maternal-fetal pharmacokinetics and fetal dose-response relationships. Ann. N Y Acad. Sci. 562, 42-55. doi: 10.1111/j.1749-6632.1989. tb21006.x

Tambour, S., Didone, V., Tirelli, E., and Quertemont, E. (2005). Dissociation between the locomotor and anxiolytic effects of acetaldehyde in the elevated plus-maze: evidence that acetaldehyde is not involved in the anxiolytic effects of ethanol in mice. Eur. Neuropsychopharmacol. 15, 655-662. doi: 10.1016/j. euroneuro.2005.04.014

Tran, T. D., Cronise, K., Marino, M. D., Jenkins, W. J., and Kelly, S. J. (2000). Critical periods for the effects of alcohol exposure on brain weight, body weight, activity and investigation. Behav. Brain Res. 116, 99-110. doi: 10.1016/s01664328(00)00263-1
Truxell, E. M., Molina, J. C., and Spear, N. E. (2007). Ethanol intake in the juvenile, adolescent, and adult rat: effects of age and prior exposure to ethanol. Alcohol. Clin. Exp. Res. 31, 755-765. doi: 10.1111/j.1530-0277.2007. 00358.x

Truxell, E., and Spear, N. E. (2004). Immediate acceptance of ethanol in infant rats: ontogenetic differences with moderate but not high ethanol concentration. Alcohol. Clin. Exp. Res. 28, 1200-1211. doi: 10.1097/01.alc.0000134220. 34842.18

Varendi, H., Porter, R., and Winberg, J. (2010). Attractiveness of amniotic fluid odor: evidence of prenatal olfactory learning? Acta Paediatr. 85, 1223-1227. doi: 10.1111/j.1651-2227.1996.tb18233.x

Walker, B. M., and Koob, G. F. (2008). Pharmacological evidence for a motivational role of $\kappa$-opioid systems in ethanol dependence. Neuropsychopharmacology 33, 643-652. doi: 10.1038/sj.npp.1301438

Weinberg, J., Taylor, A. N., and Gianoulakis, C. (1996). Fetal ethanol exposure: hypothalamic-pituitary-adrenal and $\beta$-endorphin responses to repeated stress. Alcohol. Clin. Exp. Res. 20, 122-131. doi: 10.1111/j.1530-0277.1996. tb01054.x

Wille-Bille, A., Miranda-Morales, R. S., Pucci, M., Bellia, F., D’Addario, C., and Pautassi, R. M. (2018). Prenatal ethanol induces an anxiety phenotype and alters expression of dynorphin and nociceptin/orphanin FQ genes. Prog. Neuropsychopharmacol. Biol. Psychiatry 85, 77-88. doi: 10.1016/j.pnpbp.2018. 04.005

Wise, R. A., and Bozarth, M. A. (1987). A psychomotor stimulant theory of addiction. Psychol. Rev. 94, 469-492. doi: 10.1037/0033-295x.94.4.469

Yates, W. R., Cadoret, R. J., Troughton, E. P., Stewart, M., and Giunta, T. S. (1998). Effect of fetal alcohol exposure on adult symptoms of nicotine, alcohol, and drug dependence. Alcohol. Clin. Exp. Res. 22, 914-920. doi: 10.1111/j.15300277.1998.tb03889.x

Youngentob, S. L., and Glendinning, J. I. (2009). Fetal ethanol exposure increases ethanol intake by making it smell and taste better. Proc. Natl. Acad. Sci. U S A 106, 5359-5364. doi: 10.1073/pnas.0809804106

Youngentob, S. L., Kent, P. F., Sheehe, P. R., Molina, J. C., Spear, N. E., and Youngentob, L. M. (2007). Experience-induced fetal plasticity: the effect of gestational ethanol exposure on the behavioral and neurophysiologic olfactory response to ethanol odor in early postnatal and adult rats. Behav. Neurosci. 121, 1293-1305. doi: 10.1037/0735-7044.121.6.1293

Youngentob, S. L., Kent, P. F., and Youngentob, L. M. (2012). Gestational naltrexone ameliorates fetal ethanol exposures enhancing effect on the postnatal behavioral and neural response to ethanol. Exp. Biol. Med. 237, 1197-1208. doi: 10.1258/ebm.2012.012132

Conflict of Interest: The authors declare that the research was conducted in the absence of any commercial or financial relationships that could be construed as a potential conflict of interest.

Copyright (C) 2020 Miranda-Morales, D'Aloisio, Anunziata, Abate and Molina. This is an open-access article distributed under the terms of the Creative Commons Attribution License (CC BY). The use, distribution or reproduction in other forums is permitted, provided the original author(s) and the copyright owner(s) are credited and that the original publication in this journal is cited, in accordance with accepted academic practice. No use, distribution or reproduction is permitted which does not comply with these terms. 